Journal of Al-Azhar University Engineering Sector

Vol.15, No. 57, October, 2020, 1227-1239

\title{
HUMANIZING CITIES BETWEEN REALITY AND APPLICATION
}

\author{
Ahmed Salah Ibrahim ${ }^{1}$, Mohamed Abdel Aziz Abdel Hamid ${ }^{2}$, and Mohmoud Aly \\ Ahmed $^{2}$ \\ ${ }^{1}$ Department of Urban Planning Engineering, Thebes Higher Institute of Engineering, \\ Cairo, Egypt. \\ ${ }^{2}$ Department of Urban Planning Engineering, Faculty of Engineering, Al-Azhar University, \\ Cairo, Egypt. \\ *Corresponding Author E-mail: asi_arch@yahoo.com
}

\begin{abstract}
:
Man has occupied a central role in building the city and setting up Civilization in general in order to harness all the capabilities of civilization and nature and even what the city produces to serve him and to meet his needs. The idea of human centrality has continued and still dominates the philosophy of establishing and building cities. It is agreed that urban design and planning processes aim to create a concrete (built) environment in line with the requirements, needs, and behaviors of its users. Studies have shown that urban spaces that do not satisfy the social and entertainment requirements of users lead to negative effects on those individuals (environmental, behavioral, economic, social \& cultural), which may lead to: either abandoning these urban spaces or trying to make adjustments to them in line with their requirements and behaviors or individuals acquire new behaviors to cope with these voids, which leads to urban environment deformation and the loss of the job for which it was designed.

From this standpoint, this research is concerned with presenting the direction of humanizing cities. Attention to this direction came after it became clear that the design of cities in most Arab societies was not to serve man in the first place, but was designed to serve the car, instead. When we look at our cities from the plane we see them beautiful and dazzling, while when we get closer to them on the ground, we do not feel any details of this beauty, as if all theories of modernity in urban planning that equated the environment and society of the Arab city with its counterparts in northern Canada or in the jungles of Africa were only a trick.

Those theories did not take inspiration from the concepts of our traditional cities, as they have nothing to do with our environment, customs \& traditions, and do not take in consideration the rectifiers of our history and present. Actually, we shall worry now about the future, as many chronic diseases and social customs have appeared and spread as a result of those designs. The research had reached the elements of the human city and mentioned some examples of achieving humanization of the city in many countries, whether they are Western or Middle East countries. This can help in designing and planning the city in a way that provides human needs and requirements and helps increasing user's satisfaction. The research had also given illustrative summary of the recommendations, directives, and associated rates.
\end{abstract}

\section{KEYWORDS: Humanize the cities, humanization principles of cities, Sustainable Design, Urban Areas, and Human Experiences.}




\section{انسنة المدن بين واقع المدينة والتطبيق}

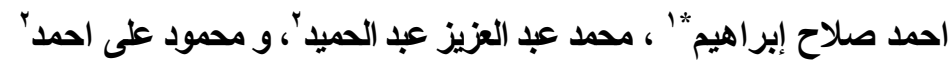

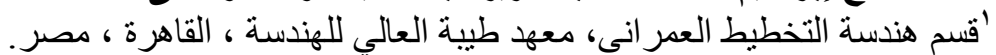

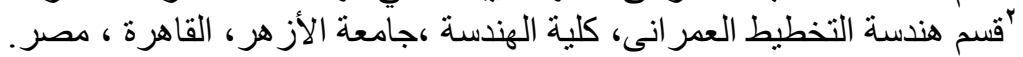

E-mail: asi_arch@yahoo.com البريد الاليكتروني للباحث الرئيسية

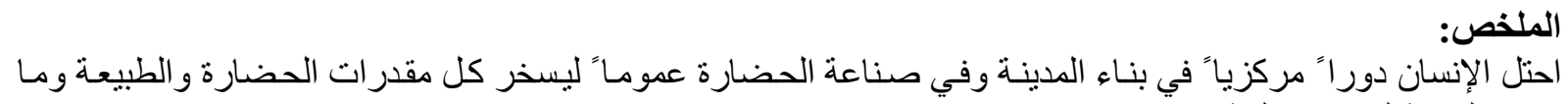

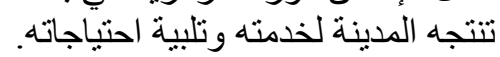

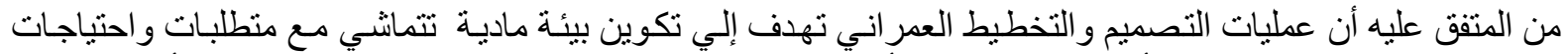

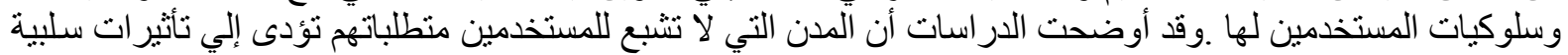

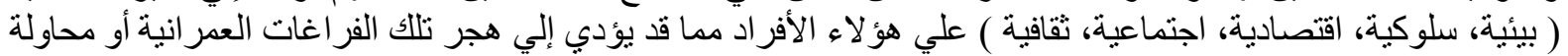

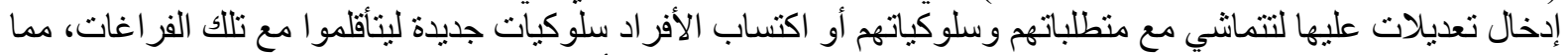

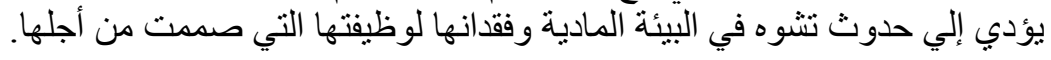

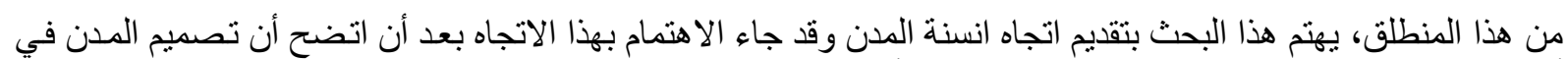
أغلب المجتمعات العربية لم يكن ليخدم الإنسان في الأصل، بل صمد لئل ليخدم السيارة.

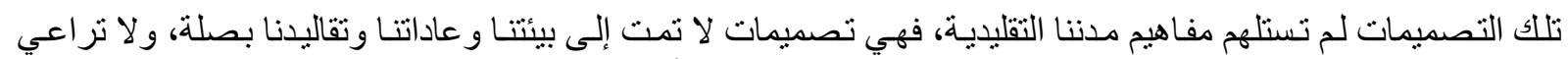

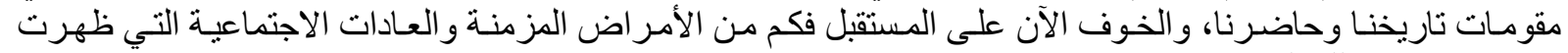
و انتشرت نتيجة تلك التصات التصاميح.

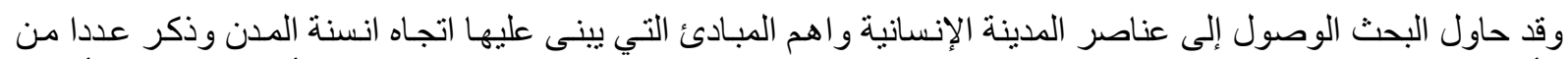

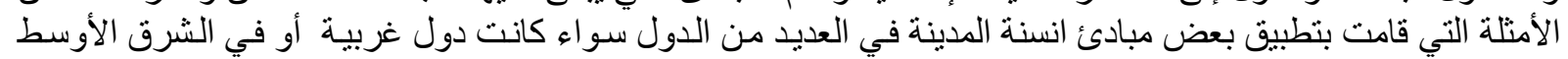

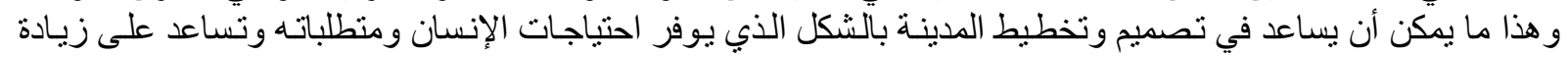
رضا المستخدمين. الكلمات المفتاحية: انسنة المدن، مبادئ انسنة المدن ، التصميم المستدام ،المناطق الحضرية ، وتجارب الاتسنة .

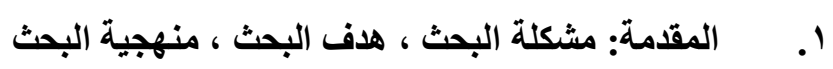

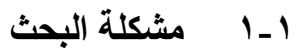

تتمثل مشكلة البحث في عدم البحث هنمام بالإنسان في تصميم وتخطيط المدن. وبالتالي فأن البحث يسعى لإيجاد إجابة على

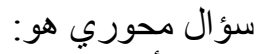

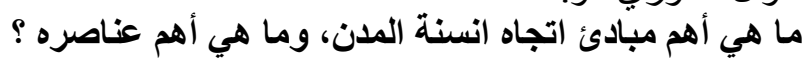

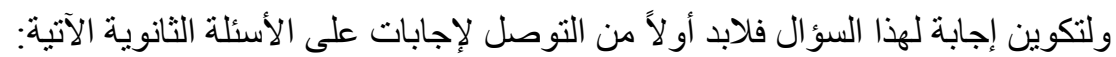

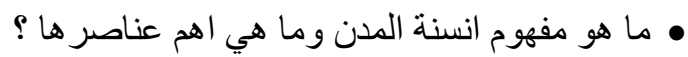

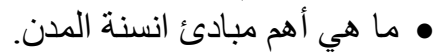

• ما هي أهم المشروعات التي حققت مفهوم انسنة المدن على المدينة ؟

هاف البحث

في محاولة للإجابة على السؤال المحوري للبحث وحل مشكلة البحث فان الهدف الرئيسي للار اسة يتمثل في محاولة

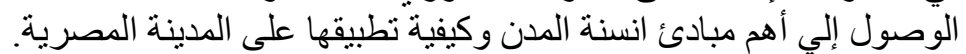

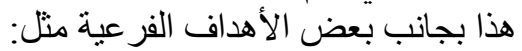

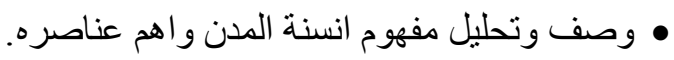
• وصف وتحليل اهم المشرو عات التي حاولت تحقيق مبادئ انسنة المدن.

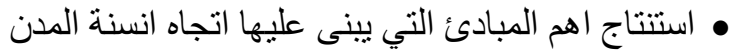

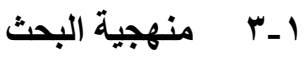

للوصول إلى الهدف الرئيسي للبحث ؛ فأن الدر اسة تعتمد على الخطو ات البحثية التالية:

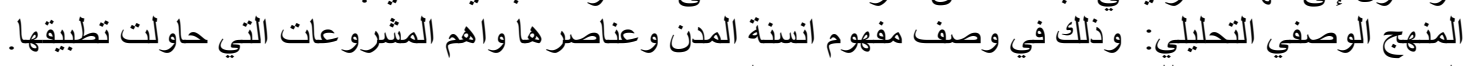
المنهج الاستنتاجي: وذلك في استنتاج اهم مبادئ النسنة المدن. 
لا يوجد تعريف متفق عليه بشأن مفهوم أنسنة المدن في أدبيات علم الاجتماع أو التخطيط العمر اني، وإن كان النان التيار الرئيسي

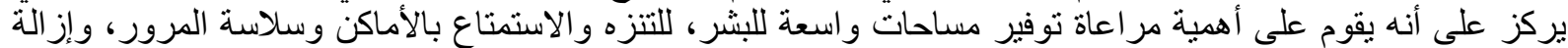

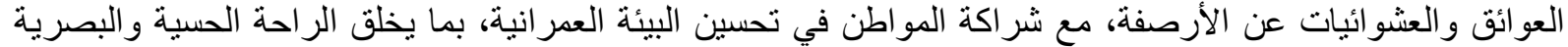

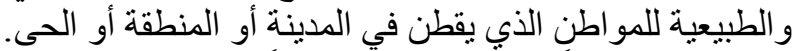

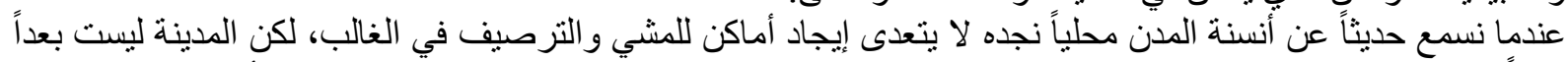

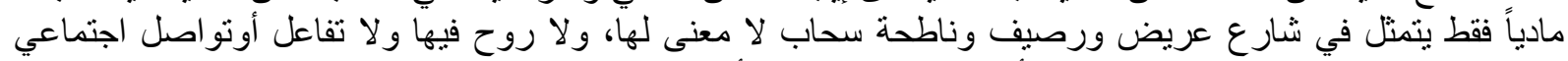

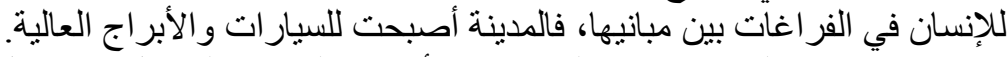

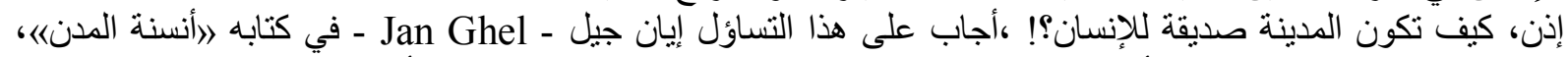

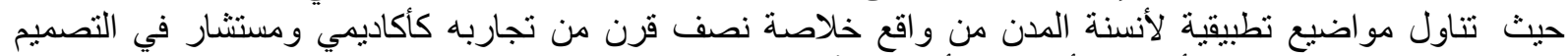

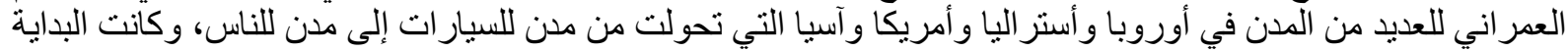

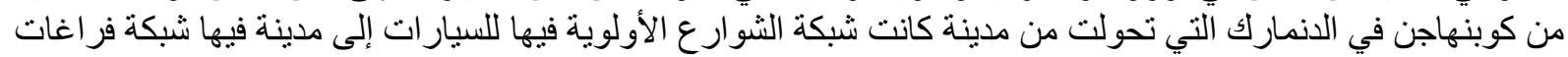
عمر انية لحركة ونشاط الإنسان.

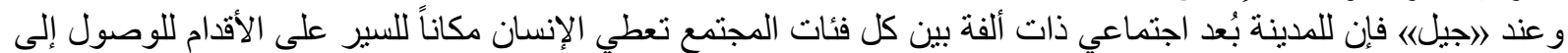

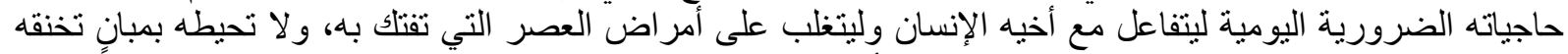

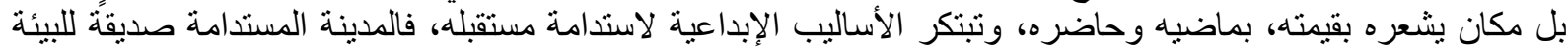

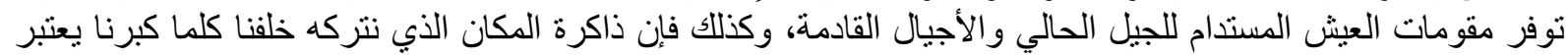
من مقومات المدن الإنسانية.

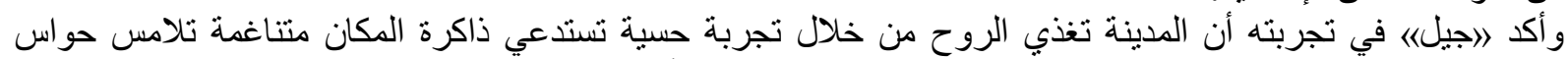

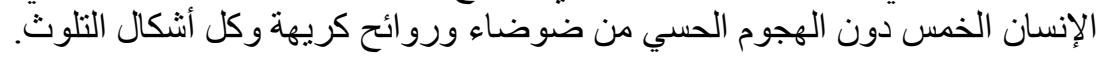

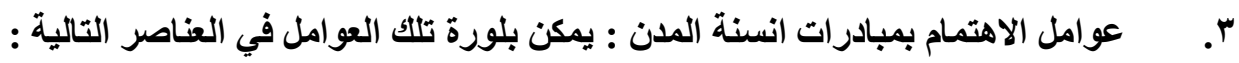

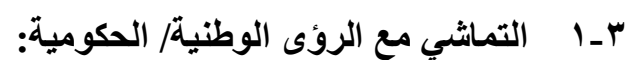

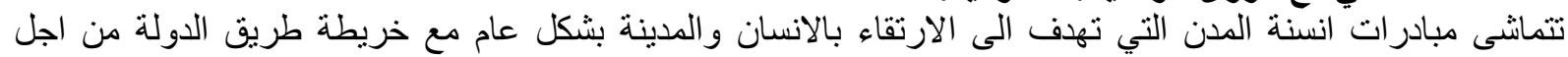

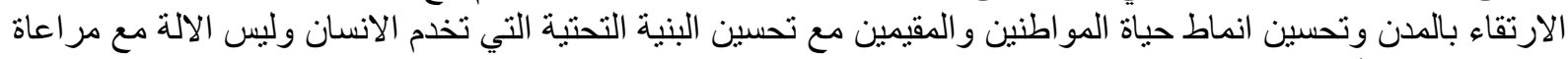
الاختلافات في النو احي الاجتماعية.

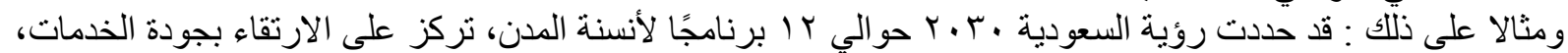

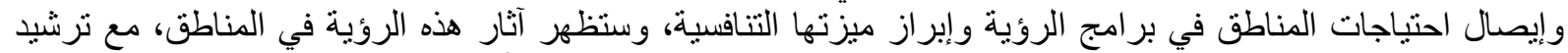

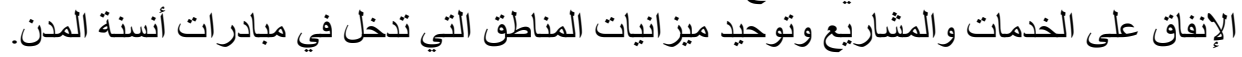

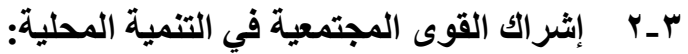

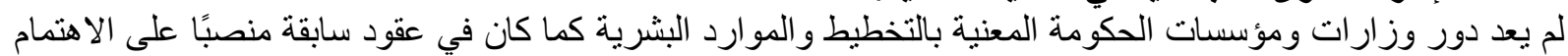

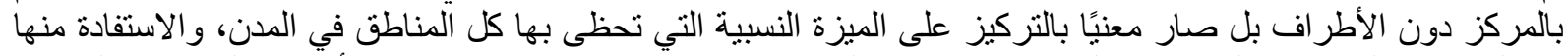

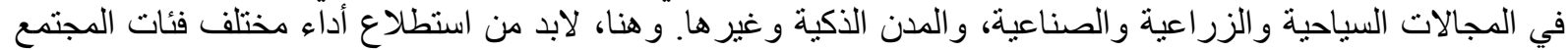

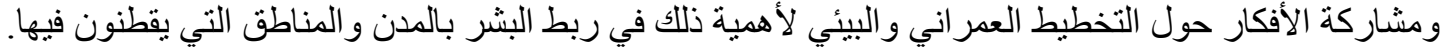

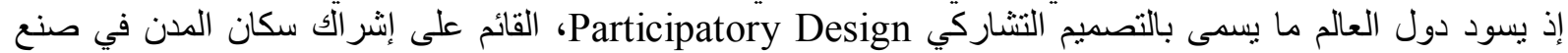

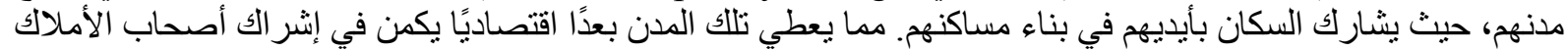

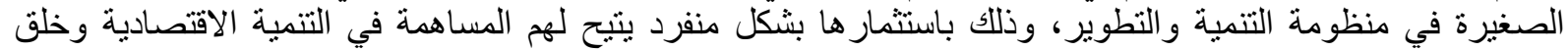

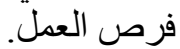
و هنا تاتي الاستفادة من آراء المواطنين في توفير المتطلبات التي يقترحونها، على نحو ما تعكسه الحدائق والمساحات

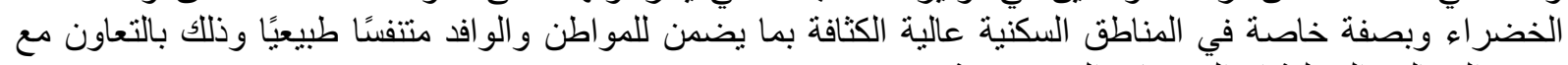
بعض المجالس المحلية او الجمعيات المتخصصة.

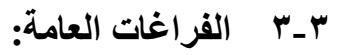

حيث يتم معالجة المناطق الفارغة والمالمة والمناطق الممتلئة داخل المدينة الواحدة، بما يعطي انطباعًا بأنها مدينتان داخل المدينة

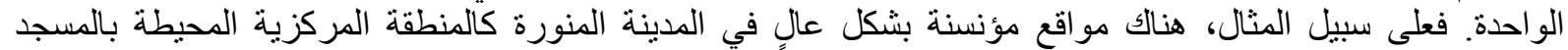

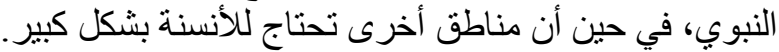

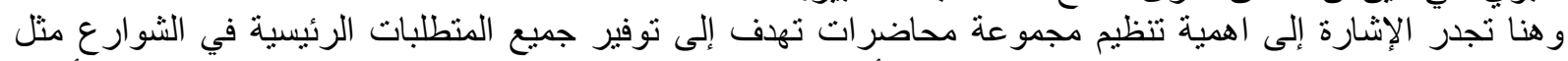

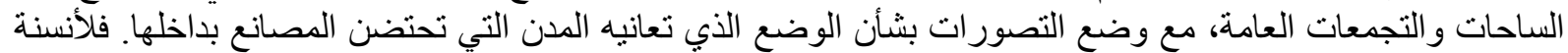


تأثير إيجابي على الموارد الطبيعية، إذ أن نوفير أماكن عامة للمشى يخفض من استهلاك وقود السبارات ويؤثر طرديًا على

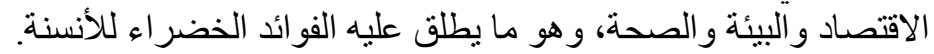

\section{ب-؛ التوازن بين الأصالة والمعاصرة:}

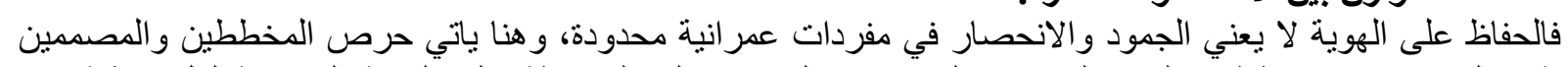

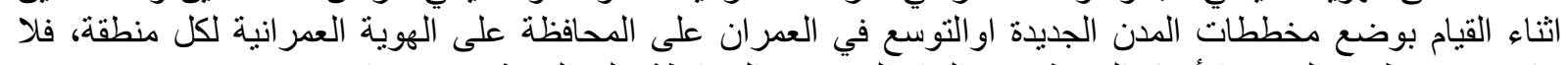

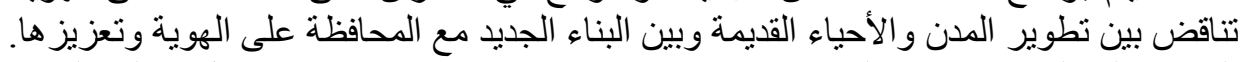

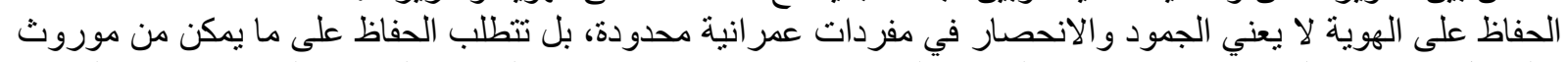

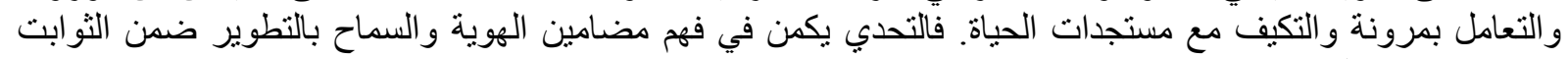
بحيث تستو عب المستجدات.

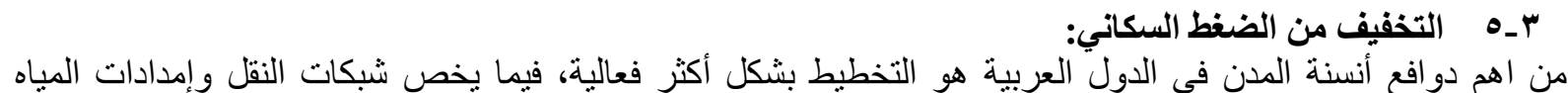

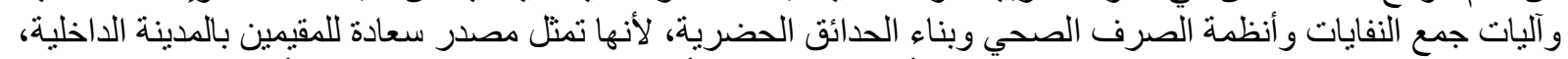

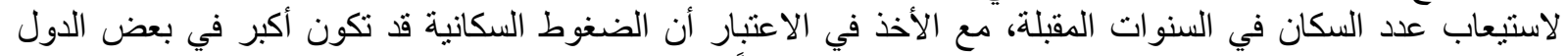

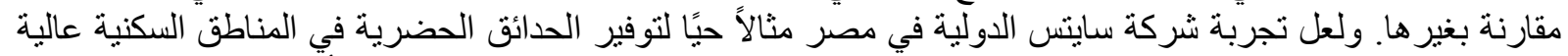

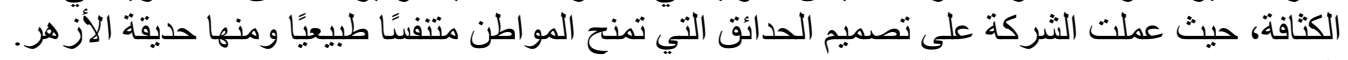

التو اكب مع ملائمة الاعتبار ات البيأية الثية:

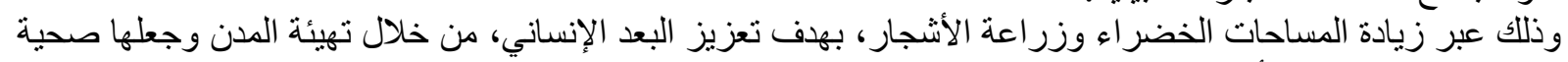

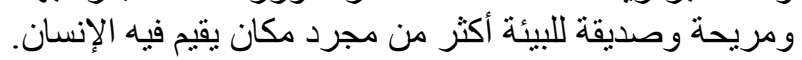

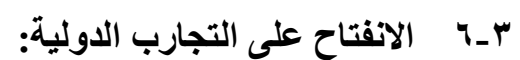

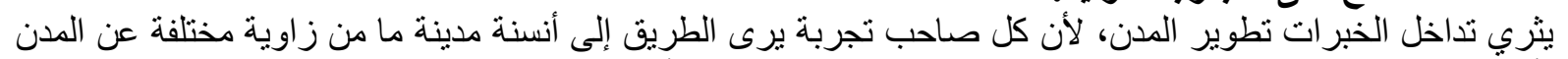

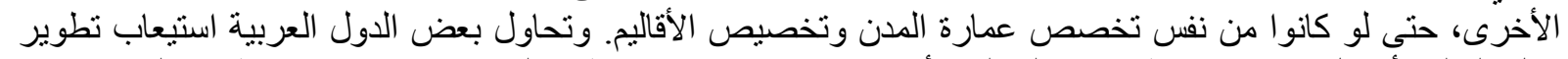

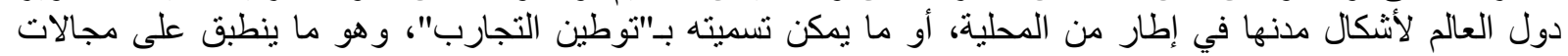

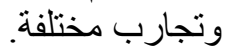

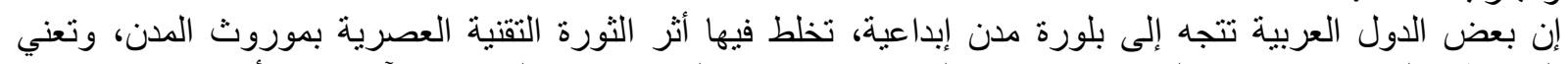

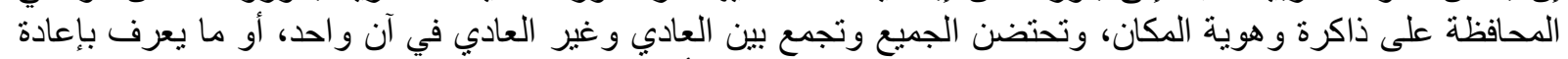

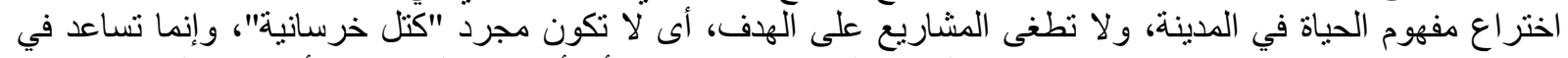

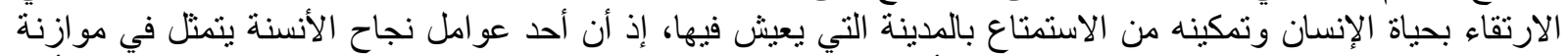

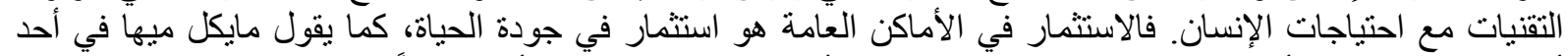

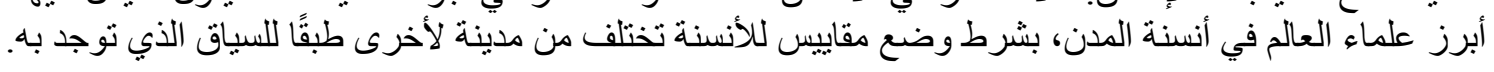

\section{؛. ـ الأثر الاقتصادي لانسنة المدن}

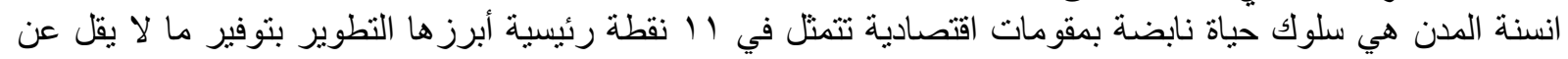

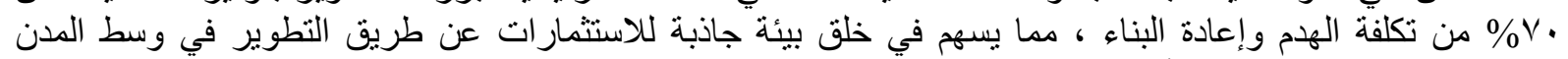

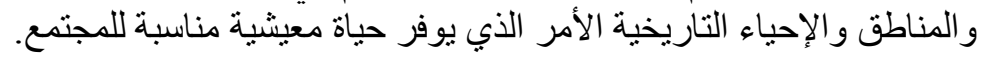

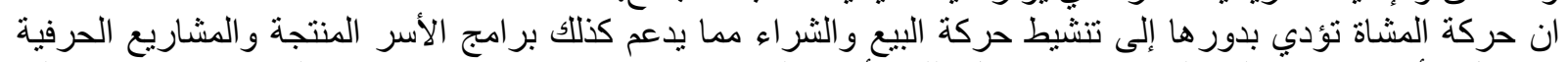

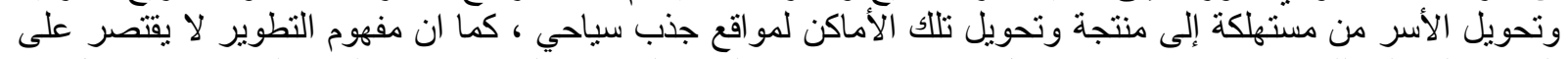

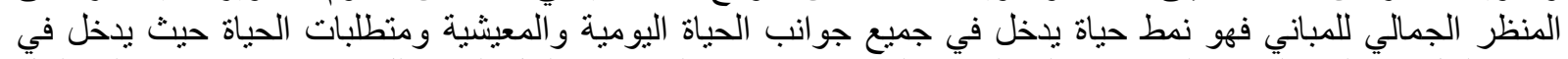

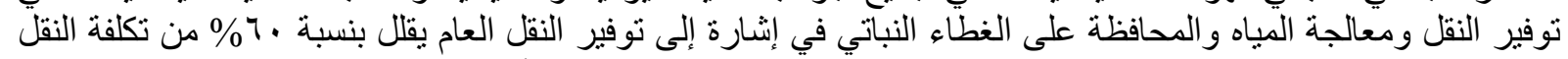

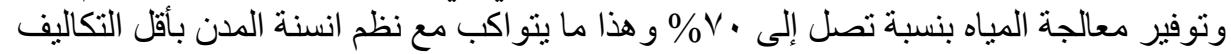

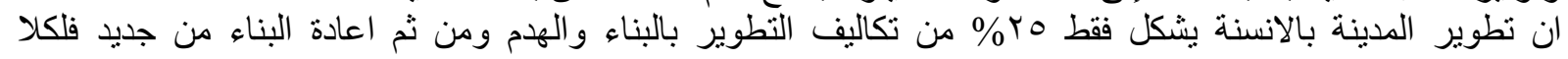

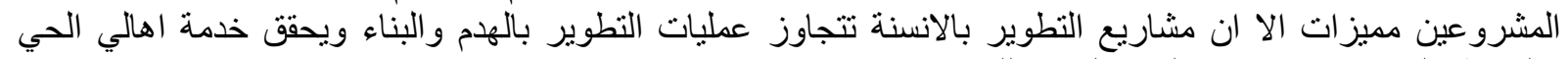

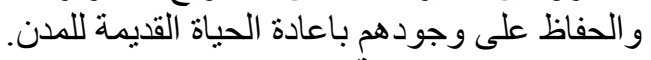

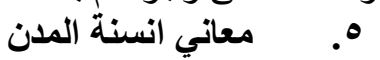

يتبنى اتجاه انسنّة المدن عدة مبادئ وقيم منها الاستدامة ـ ذكاء المدينة ـ الرفاهية ـ الجمال ـ ـ والامان ـ الصحة ( البيئة

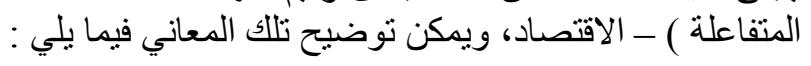




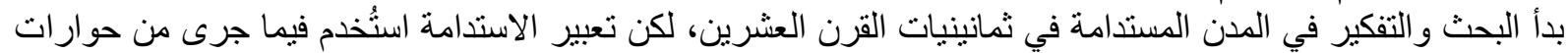

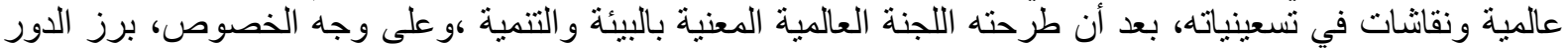

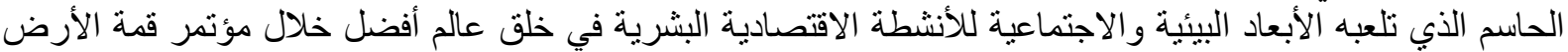

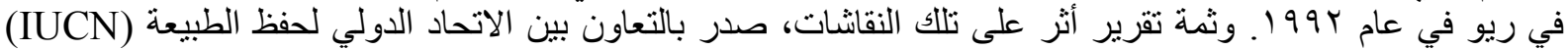

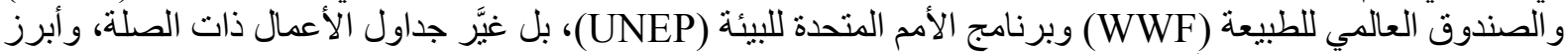

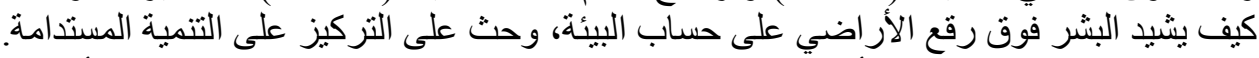

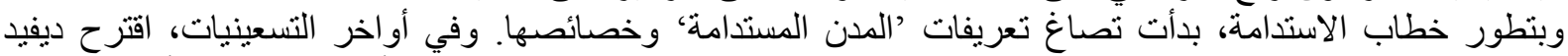

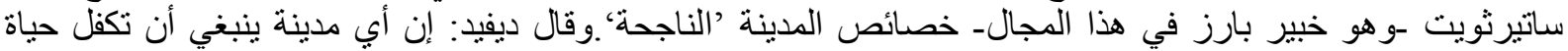

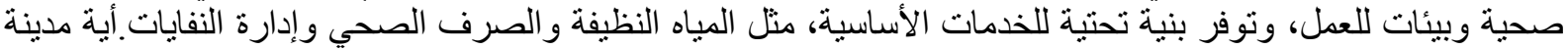

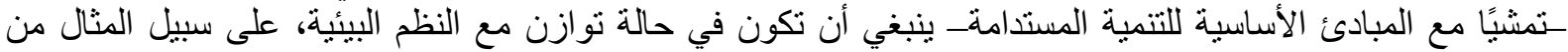

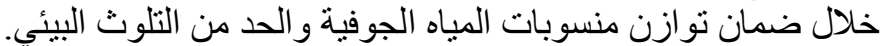

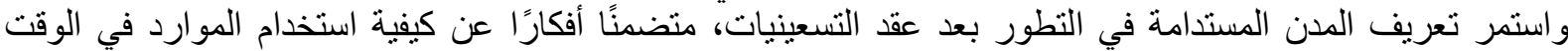

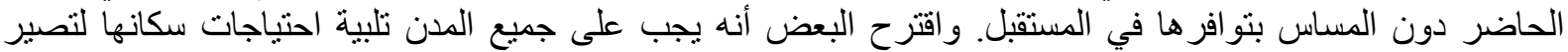

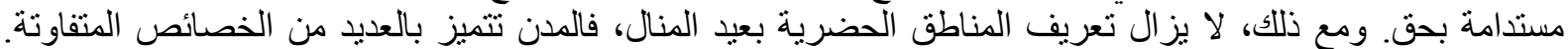

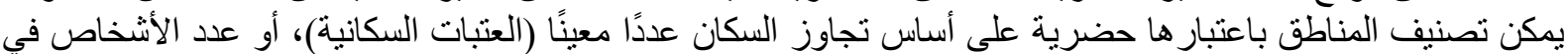

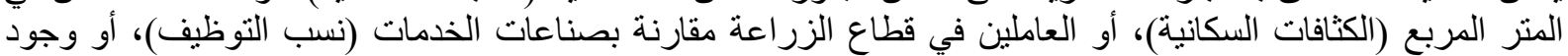

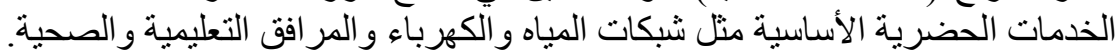

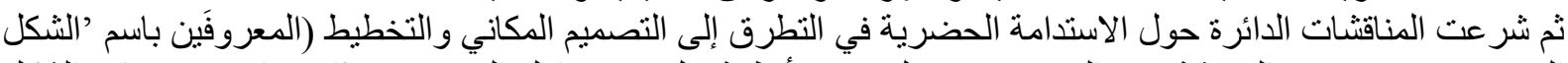

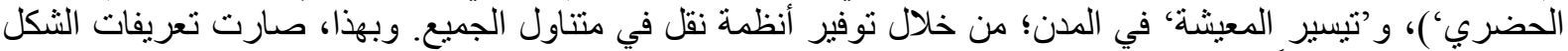

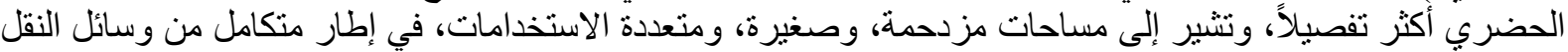

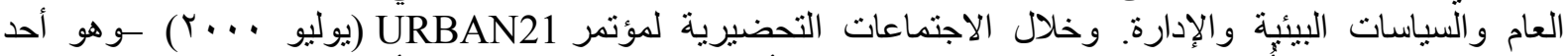

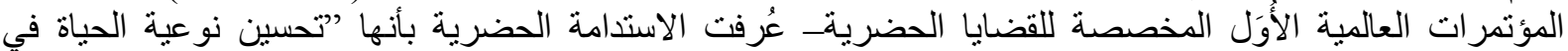

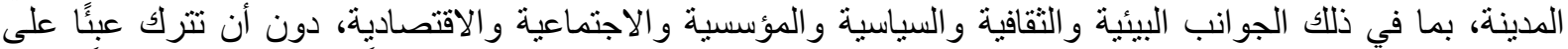

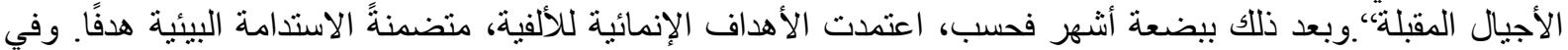

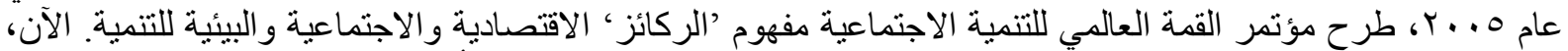

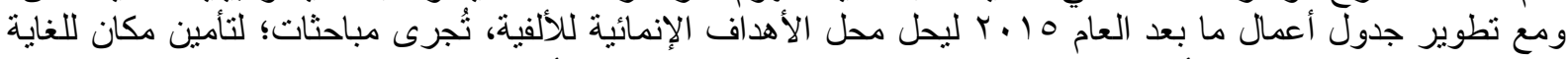

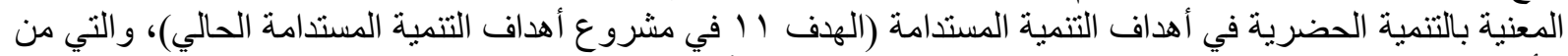

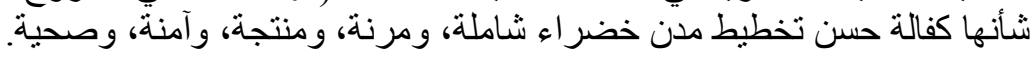

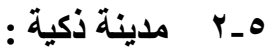

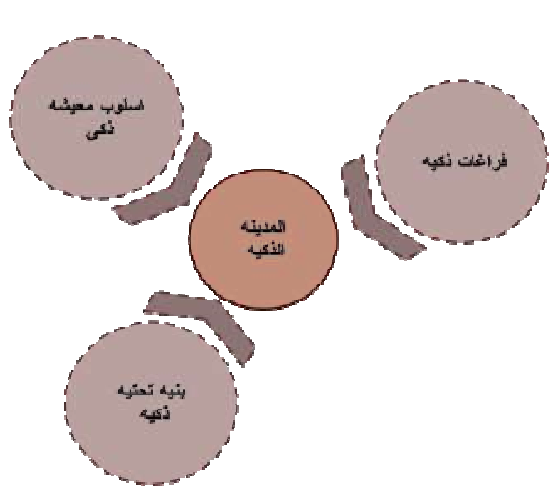

شكل رقم 1 - العناصر الأساسية للمدن الأكية ـ المصدر الباحث

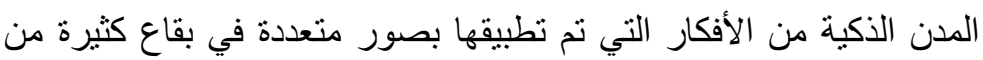

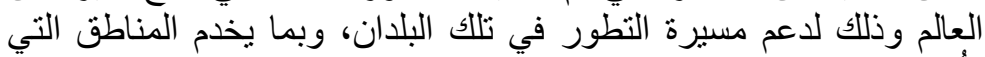

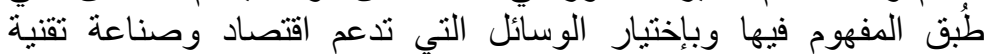

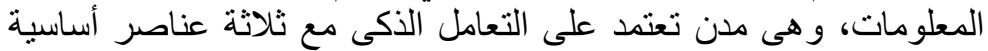

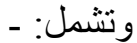

اسلوب معيشة ذكى: حيث أن أغلب القانطين فيها لديهم القدرة على التعامل

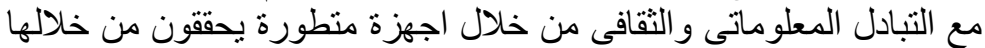

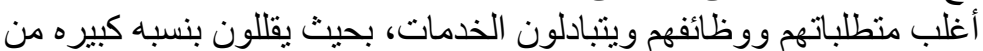
سلبيات التصرفات الحيات الحياتيه.

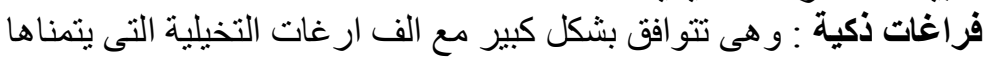

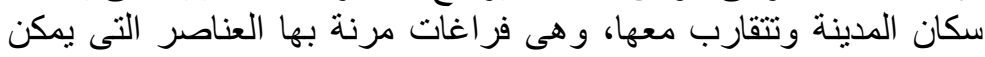

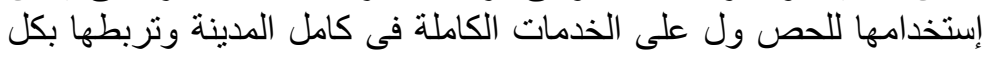
العالم.

بنية اساسية ذكية : وهى ليست فقط فى شبكة عناصر ؛ الأتصال ولكنها تكون فى كل عناصر البنية التحتية حيث يتم التوفير فى الموارد ( مياهـ طاقه ....)وكذللك يكون هناك إعادة استخدام لكل

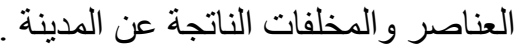
ويتم ربط هذه الثبكات و العناصر المكونة للبنية التحتية بجميع مناطق السكن والخدمات من خلال أجزة كومبيوتر تسبطر

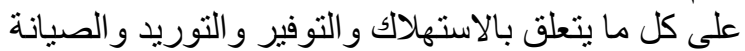

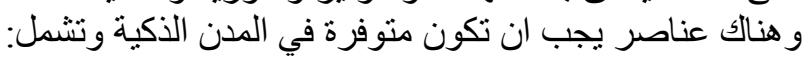




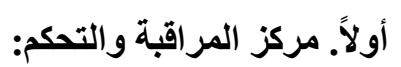

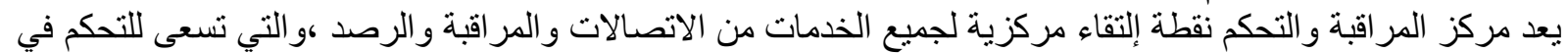

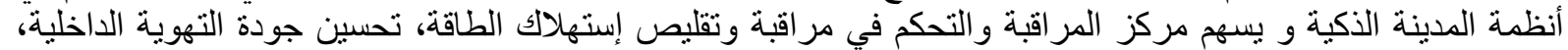

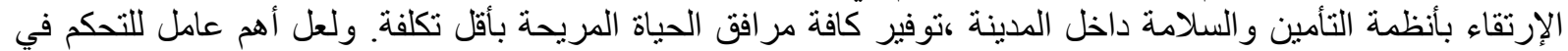

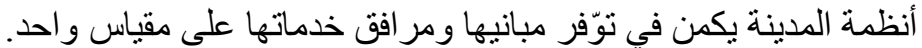

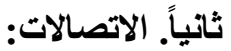

يتم تنظيم جميع خدمات الاتصات الاتصالات وتكنولوجيا المعلومات والإتصالات ،التي تحصل عليها المدينة من خلال هيئة تنظيم

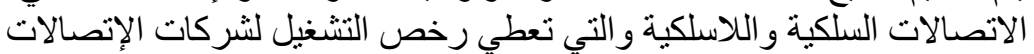

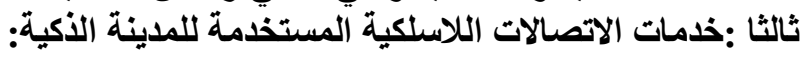

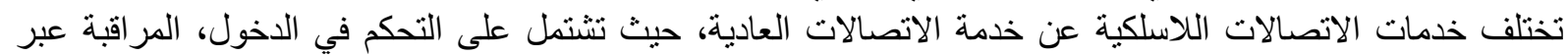

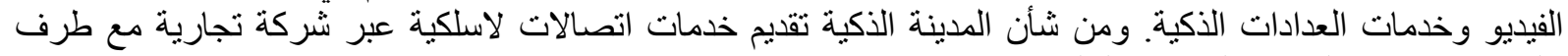

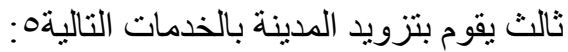

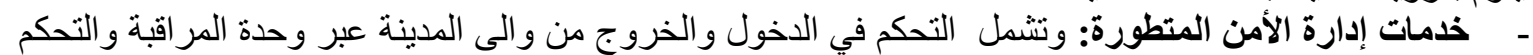

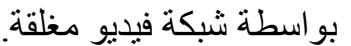
- - أنظمة تسيير المباني. و واستخدام التشغيل الآلي في المكاتب والمنازل.

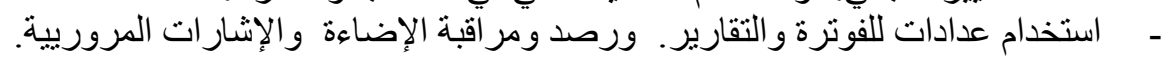

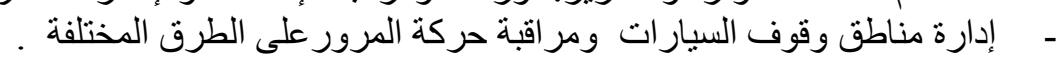

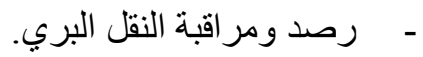

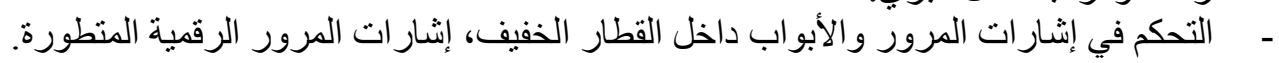

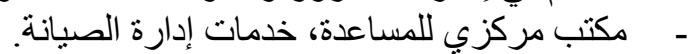

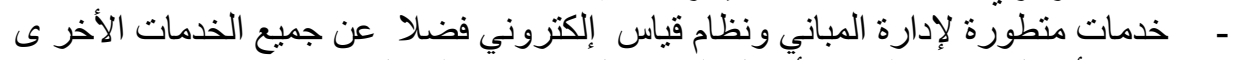

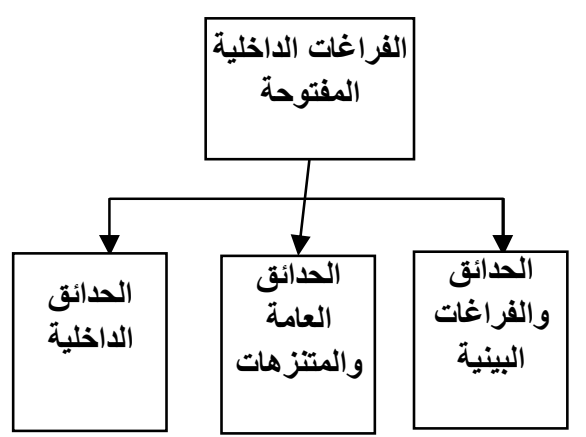

شكل رقم r ـ أنواع الفراغات الداخلية المفتوحة ـ المصدر الباحث أنمات

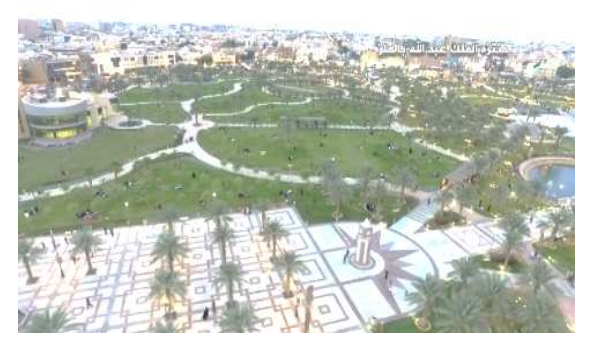

شكل رقم ب-الساحات الداخلية و العامة والمتنز هات-الرياض-الماتمات الملكة العربية العامية السعو دية الرية - - مركز أعمال متطور لاعم الأعمال التي تدخل في إطار المجال نفسه.

\section{r_o}

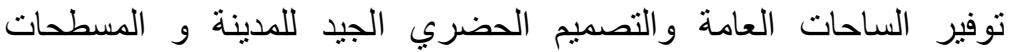
الخضر اء و الحدائق العامة يعتبر من اهم الاحتياجات التي يحتاجها الانسان في لالئي ويمكن تقسيم هذا النوع من الفر اغات كالآتى الحدائق والفراغات البينية:-

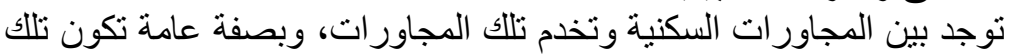

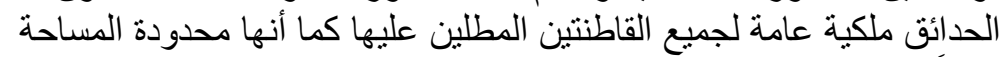

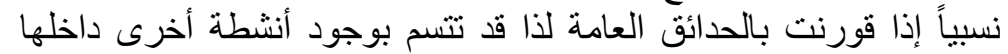

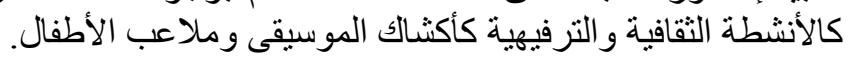

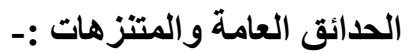

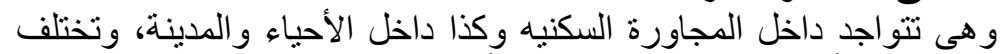

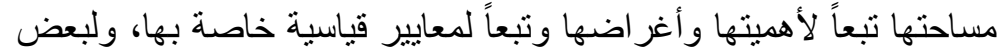

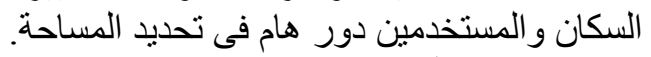
الحدائق الاخلية :- الدين

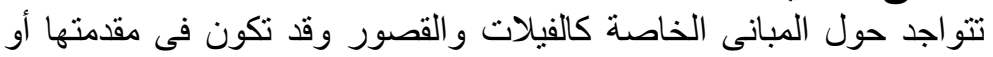

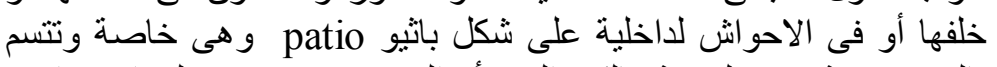

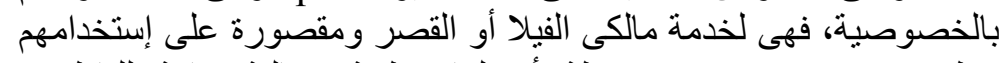
فقط ودون غير هم مع ملاحظة أن لها وظيفة جمالية الفية عامة للقاطنتين و المجاورين معاً. بـ

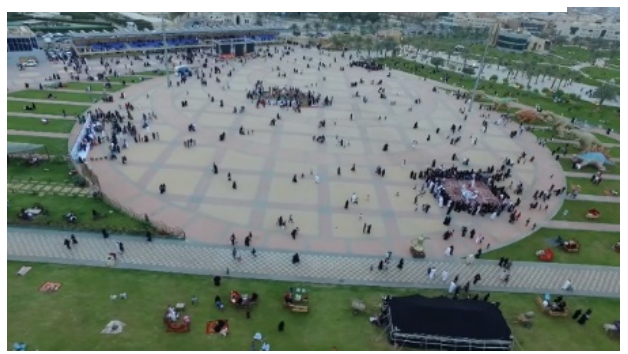

0ـ ـ مدينة عائلية

انتشار الساحات العامة واماكن التجمعات و الاحتفالات و اماكن الانشطة الاجتماعية و النو ادي الاجتماعية والماتو الرياضية. 
حيث تواجد مثل تلك الأماكن على قدرة المجتمع على التعايش في المدينة وتقبل الحياة فيها وهذا يتحقق بتوفير الأماكن

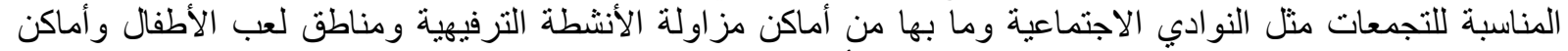

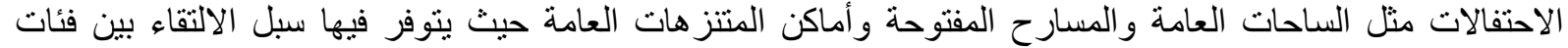

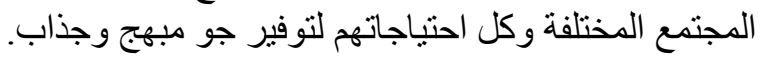

0_.

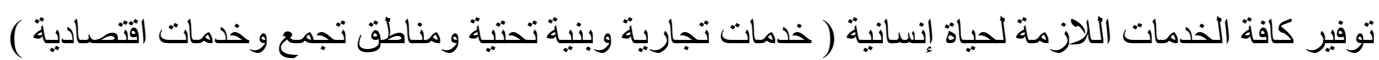

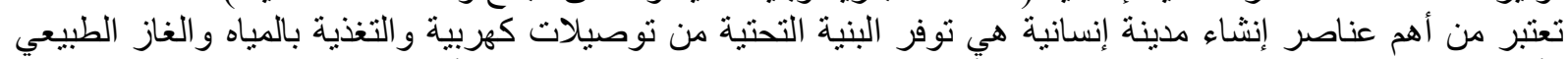

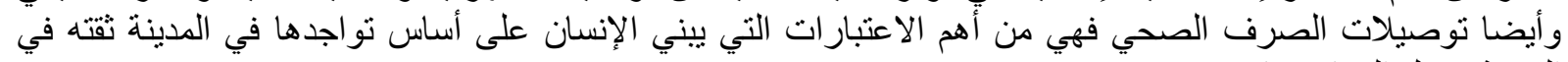

المدينة وتقبل الحياة فيها توفيا و أيضا توفر الخدمات التجارية والتي توفر بدور ها كافة الاحتياجات الإنسانية بكل مستوياتها ، على مستوى المجاورة

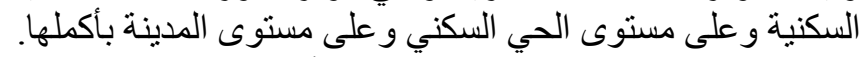

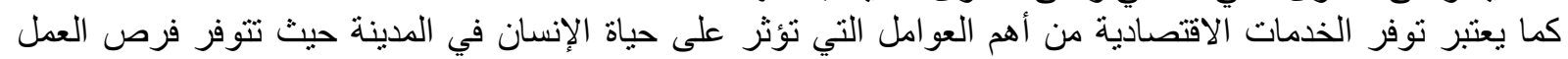

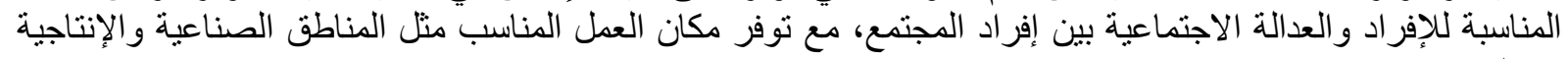
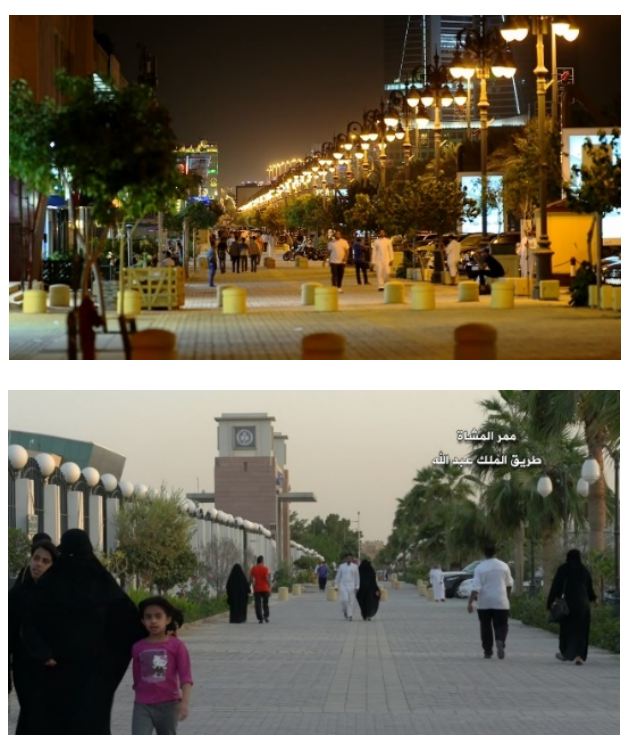

شكل رقم • - ممرات المشاة ـ الرياض - المملكة العربية السعودية
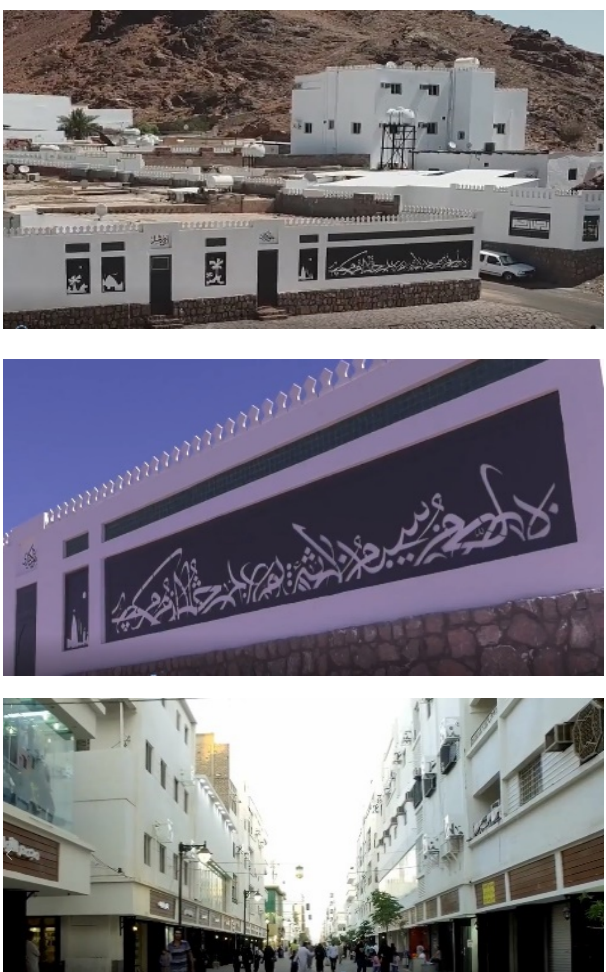

في المدينة.

1_-0

توفير المساحات اللازمة لممارسة رياضة المشي والجري ومسارات الإتهات

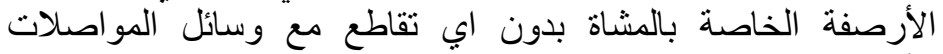

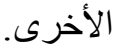

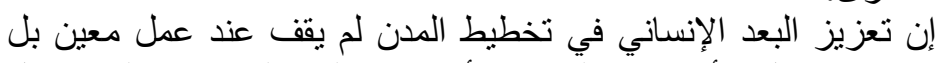

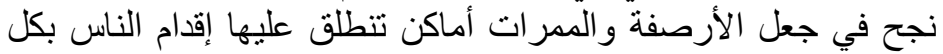

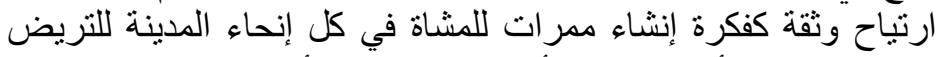

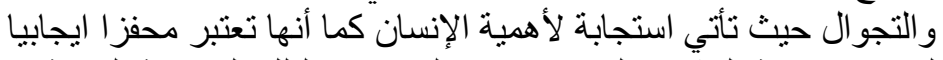

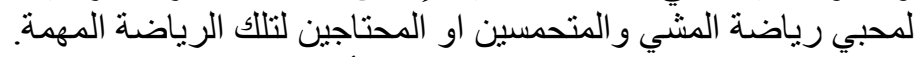

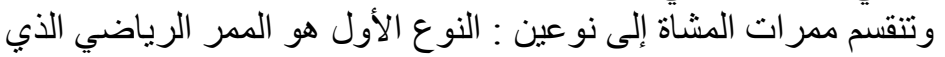

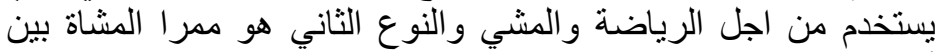

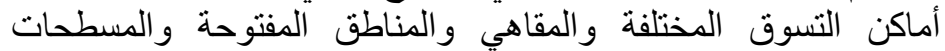
الخضر اء المخصصة النوف للجلوس عليها.

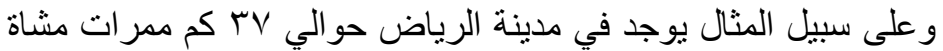

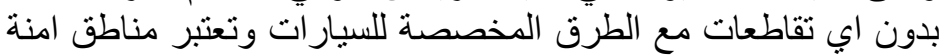

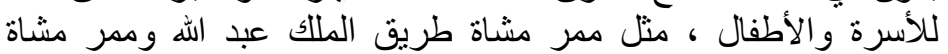
طريق الامير محمد بن عبد العزيز. V_o

تطبيق طراز معماري لمباني المدينة او المناطق داخل المديكارئل المدينة يكون

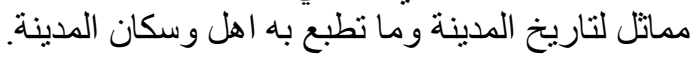

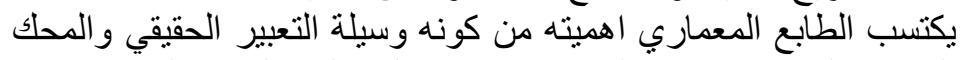

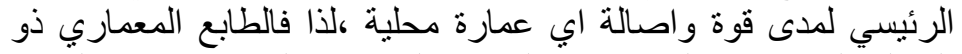

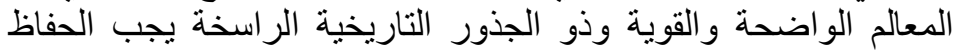

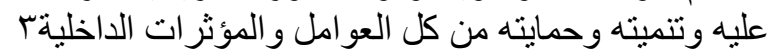

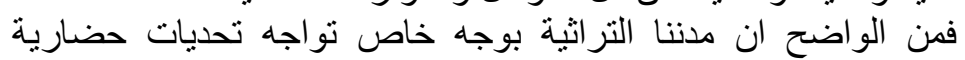

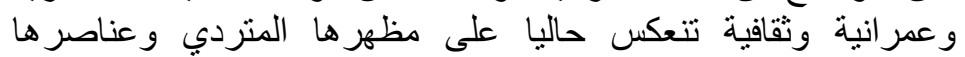

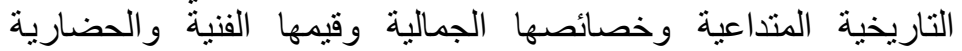

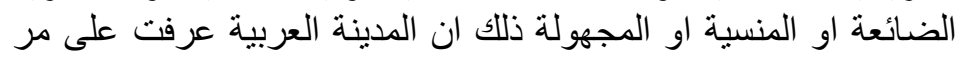

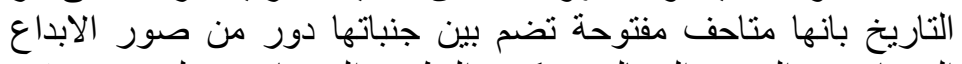

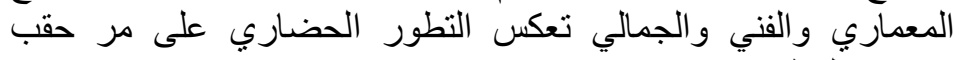

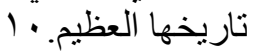

شكل رقم 1 ـ تطور الطرز المعمارية ــ المدينة

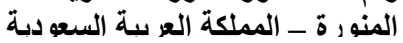


يمكن من خلال الطابع المعماري التعبير عن المهارات والمعارف المجتمعية في فن البناء ، كما يمكن من خلاله تحقيق

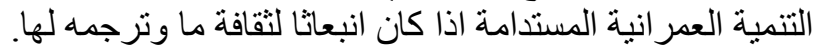

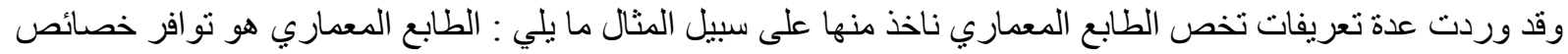

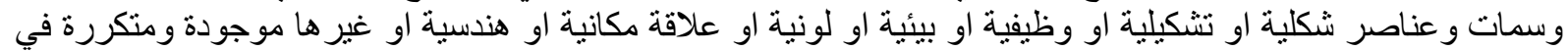

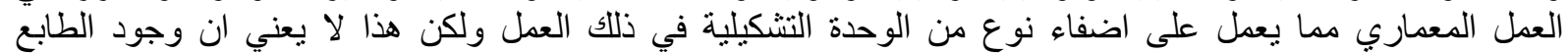

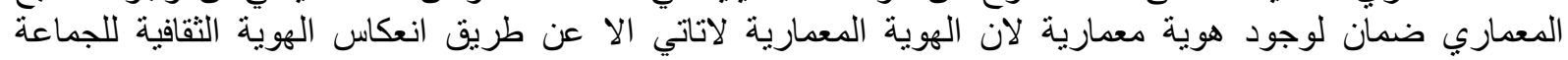

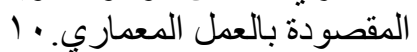

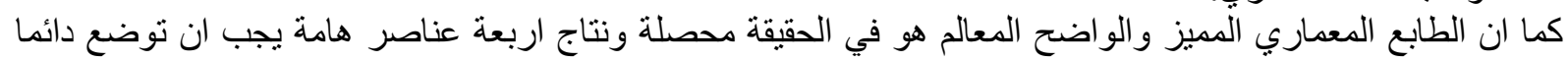

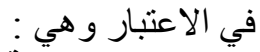

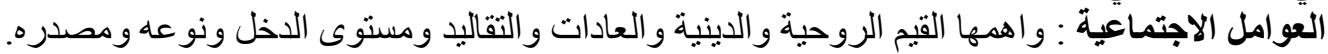

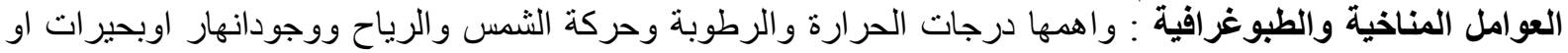
مواد البناء الطبيعية والمحلية : ويقصد بها المواد الطبيعية التي يتم صقلها وتشكيلها وتصنيعها لتوظيفها في عملية البناء

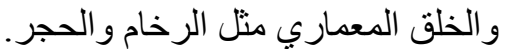
التراث الثقافي : وهو حصيلة تفاعل وتطور ثلاث جو التب اساسية في حياة اي مجتمع على مر العصور التاريخية المختلة

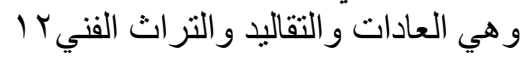

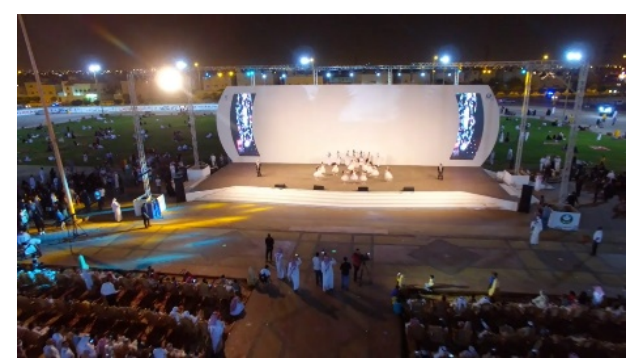

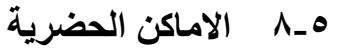

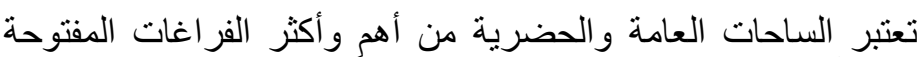

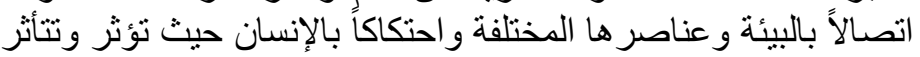

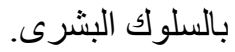

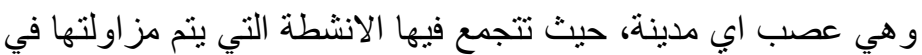

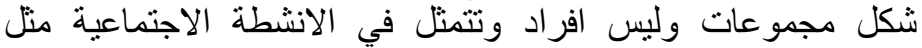

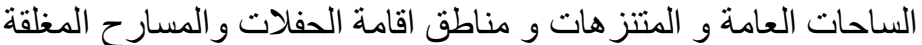

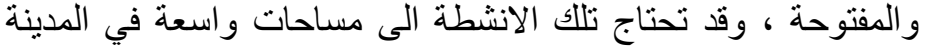

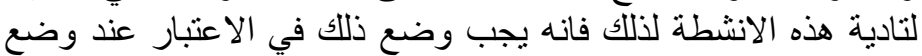

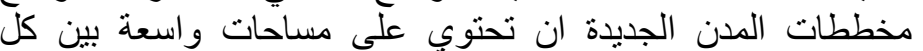
الاستعمالات المختلفة في المدينة.

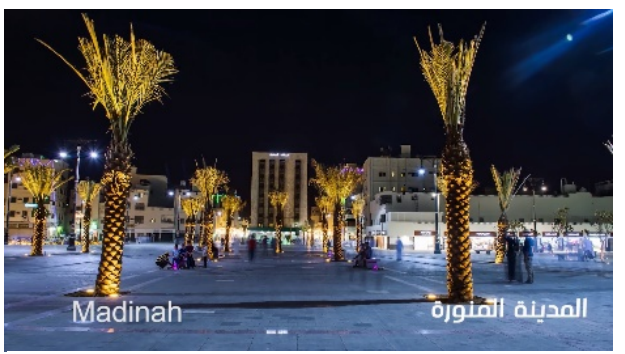

شكل رقم V-اماكن التجمعات واقامة الحفلات و

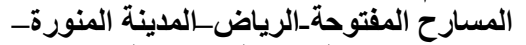

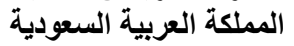

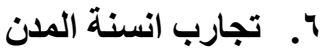

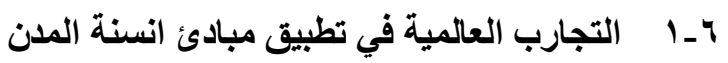

تجربة اليونسكو في انسنة المدن :

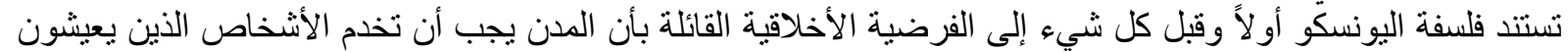

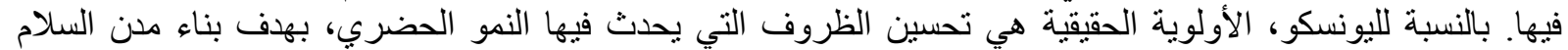

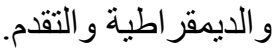

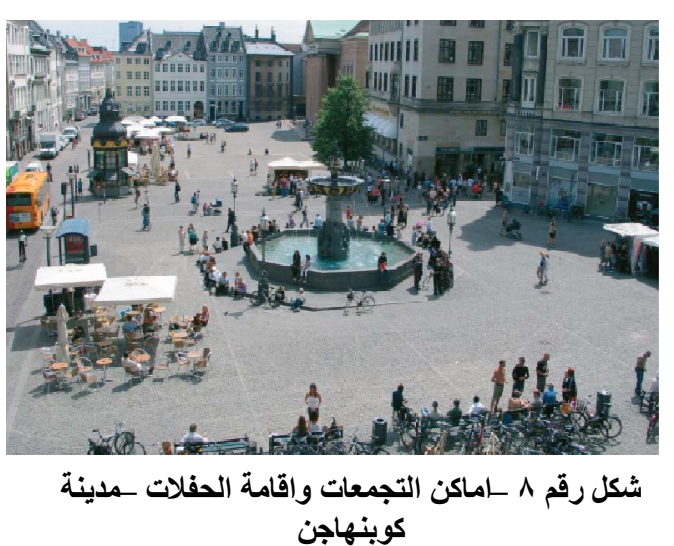

كوبنهاجن
ففي إطار مهرتها المتمثلة في تعزيز المعرفة ونشرها، تنفذ اليونسكو

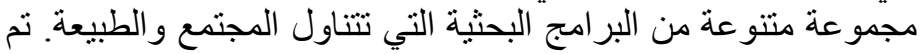
إنشاء برنامج إدارة التحولات الاجته الاجماعية (MOST) للمساهمة في

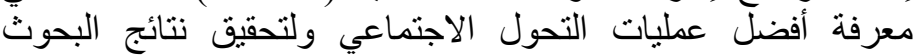

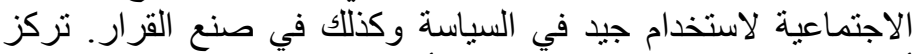
أنشطة MOST فيما يتعلق بالمدن كأماكن للتحولّ السريع في على قضايا

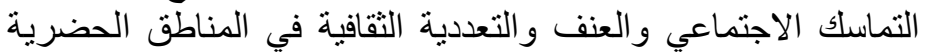

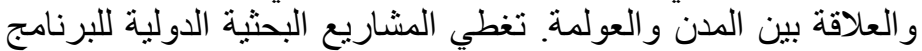

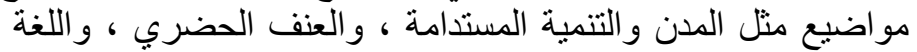


الحضرية ، وتصنيع المدن منو سطة الحجم و العولمة ، و المشكلات الخاصة بالمدن الضخمة ، و والبيئة ، وقضايا المر أة. بال

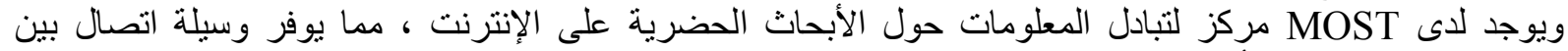

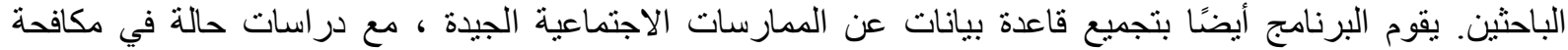
الاستبعاد الاجتماعي و الثنقافي و الفقر والعنف في المدن.

Copenhagen Modal split

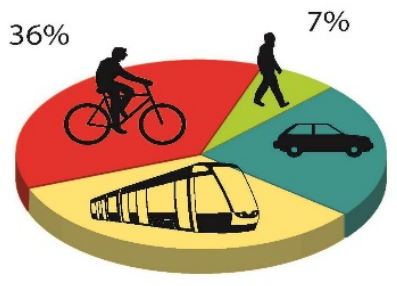

33\%

شكل رقم 9 - نسب استخدام المواصلات للمواطن في مدينة كوينهاجن
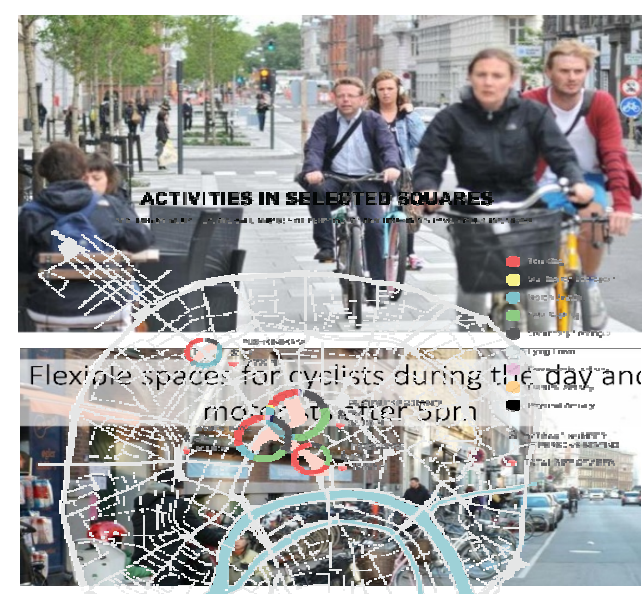

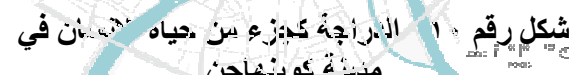

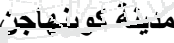

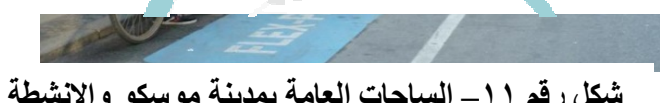
المقامة بهام بمان

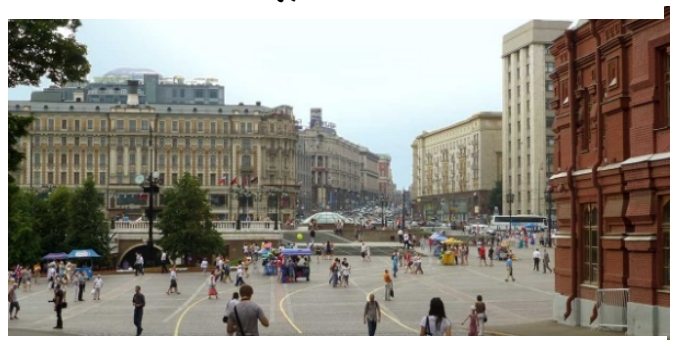

شكل رقم r 1 ا ـ احدى الساحات العامة المخصصة للمشاة - موسكو - روسيا

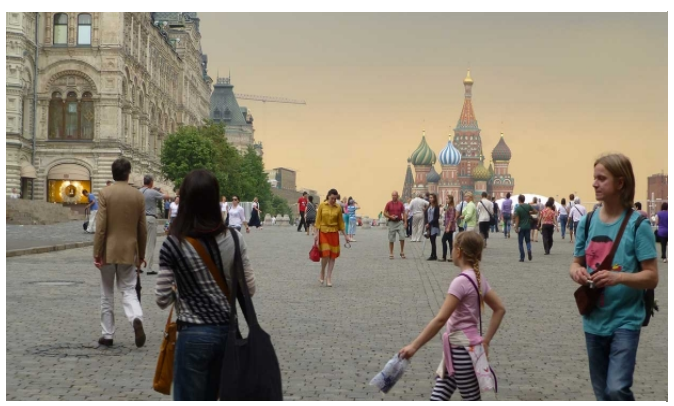

شكل رقم ب 1 ا ـ الحدى الساحات العامة المخصصة

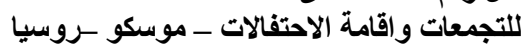

\section{- 20 - 20 - مدينة كوبنهاجن}

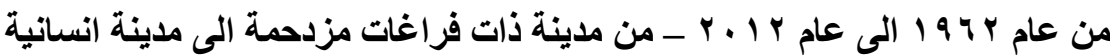

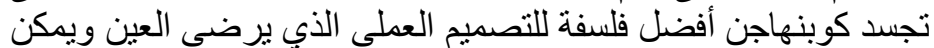
الوصول إليه لأكبر عدد من الناس. اللاسئ

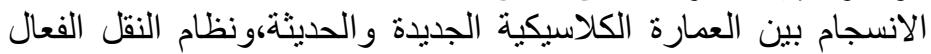

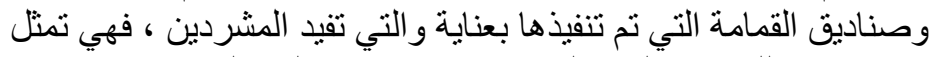

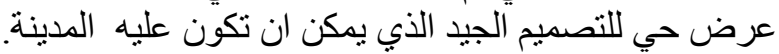

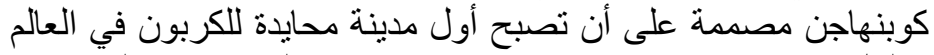

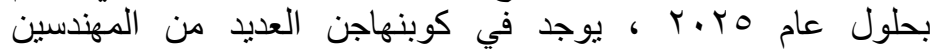

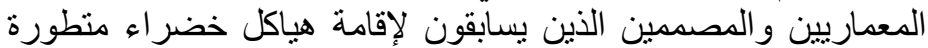

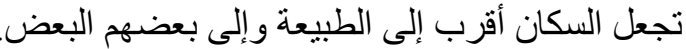

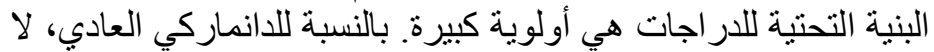

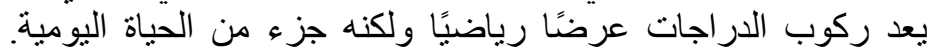

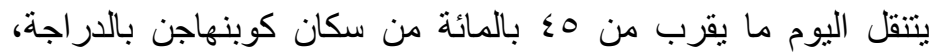

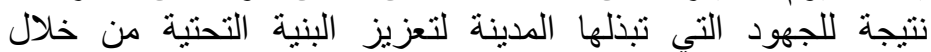

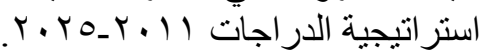

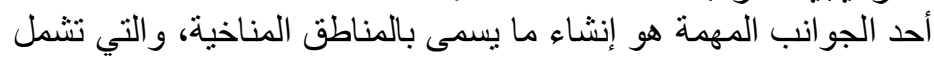

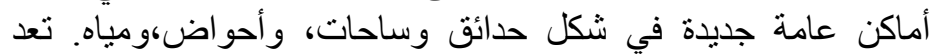

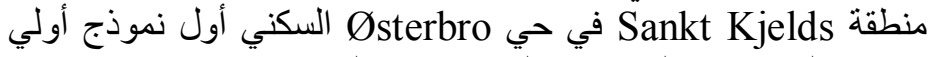
من هذا النوع ، مع المزيد من المشاريع قيد التنفيذ.

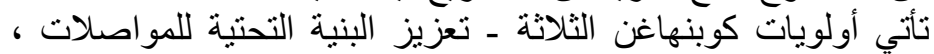

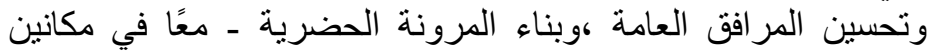

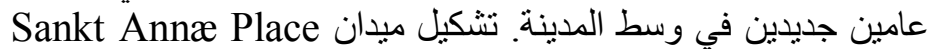

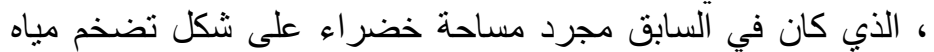
الأمطار وحوض الأي التصاص الماء. يحافظ على المظاهر المناء المنظمة جيدًا بينما يضيف استر اتيجيات مطلوبة بشدة للأحداث المناخية.

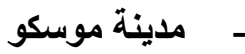

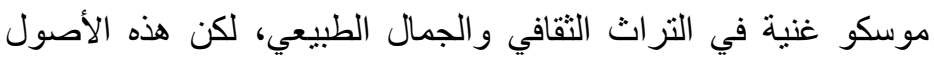

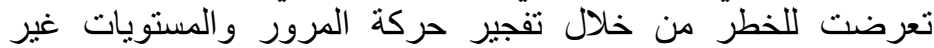

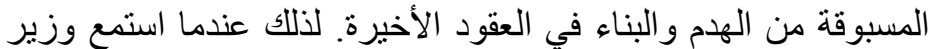

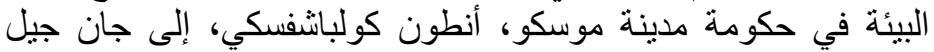

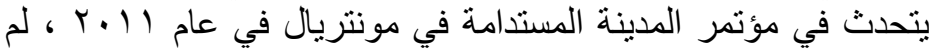

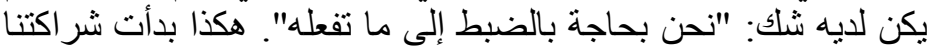

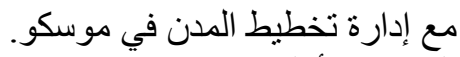

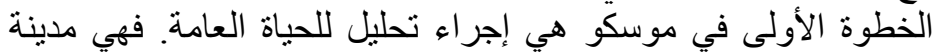

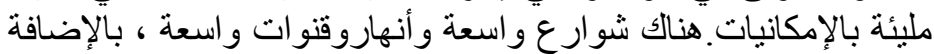

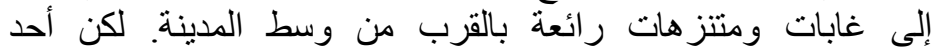
الإكتشافات الرئيسية لمسحنا لموسكو كان أن أنساء أجزاء كثيرة من المدينة

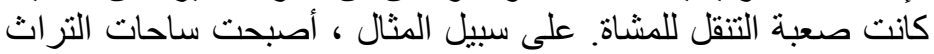

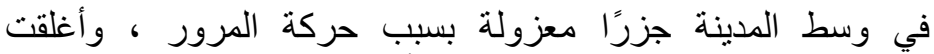
المتنز هات الجميلة في المدينة بسبب الأسوار وكان بهرئة المها مداخل قليلة ، و الطرق السريعة عبر وسط المدينة لديها معابر للمشاة محدودة. 


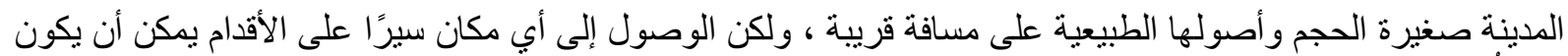

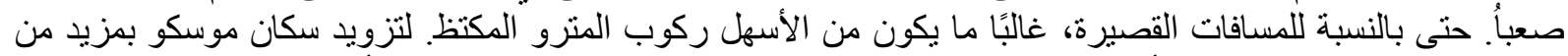
الخيارات في كيفية تحركهم في أنحاء مدينتهم ، ركزنا طاقاتنا على الاستر اتيجيات التي يمكن أن تجعل التنقل في الثوار التئر

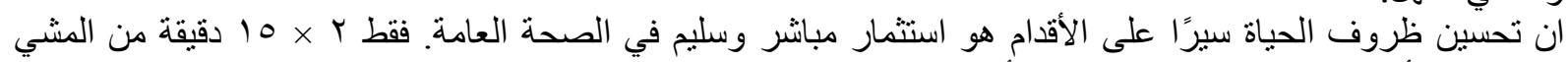

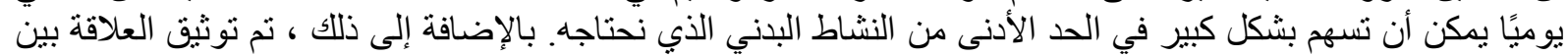

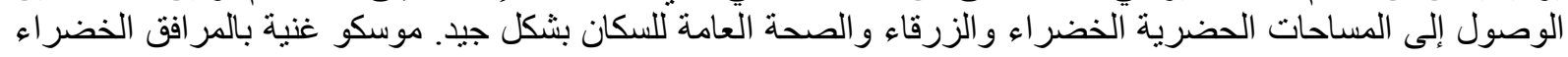

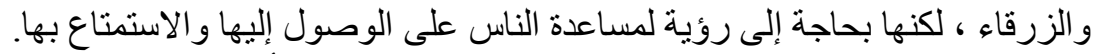

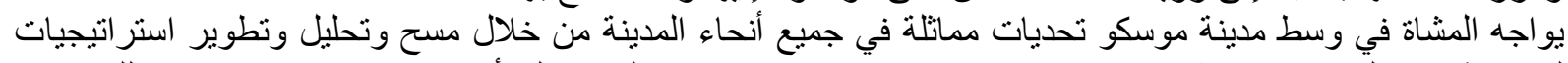

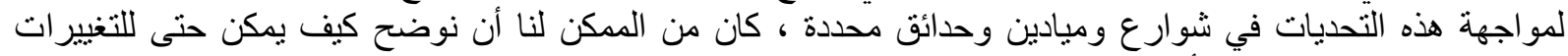

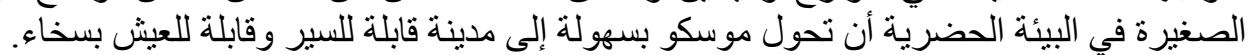

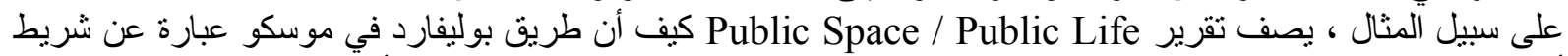

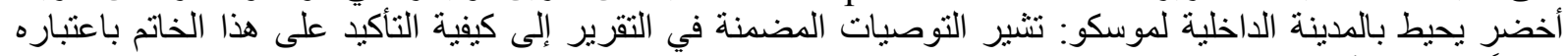

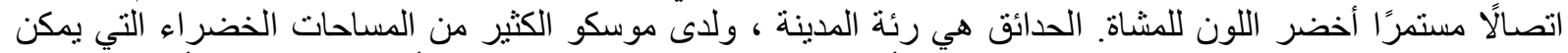

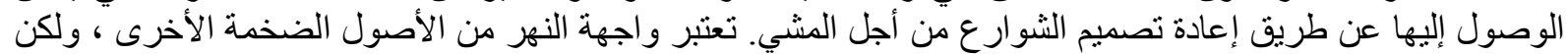

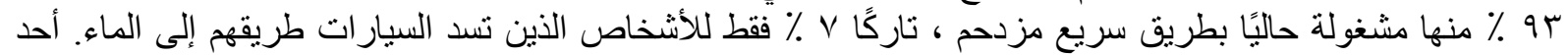

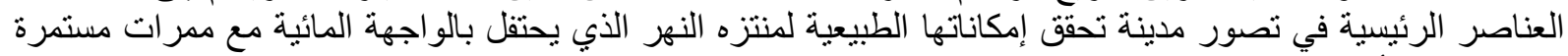

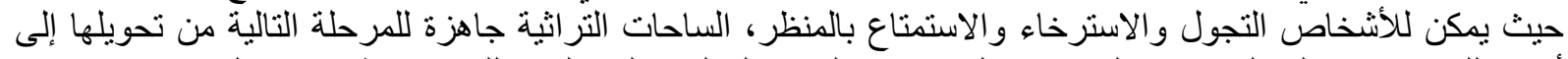

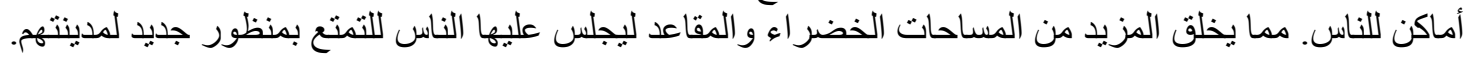

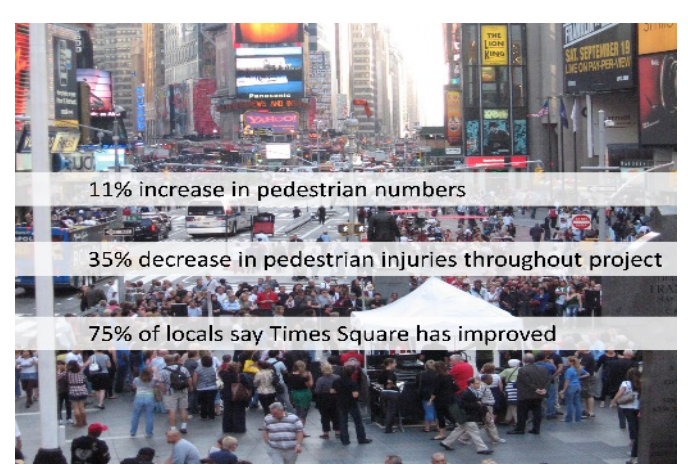

شكل رقم ؛ أ - نسب التغيرات الحادثة في مدينة نيويورك بعد تطبيقها لبعض مبادئ الأتسنة

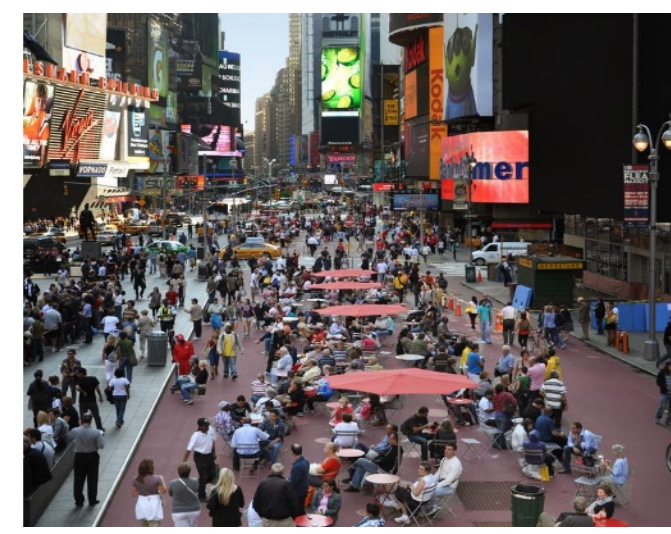

شكل رقم 10 - احدى الساحات العامة في مدينة نيويورك بعد ان كاتت طريق للسيارات العيات

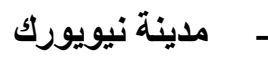

عندما يتعلق الأمر بالتصميم والهندسة المعمارية في الورية لإيات

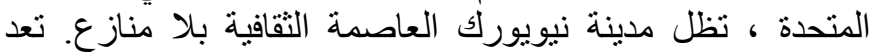

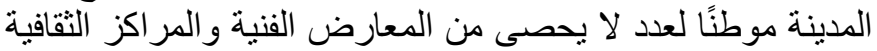

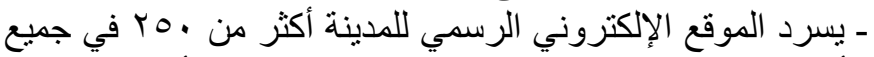

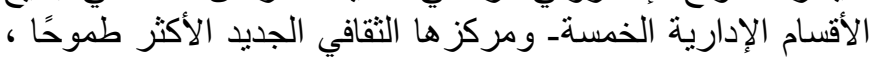

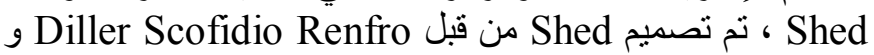

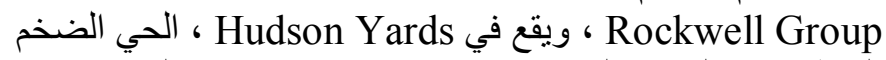

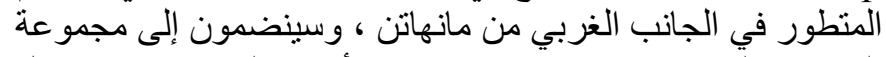

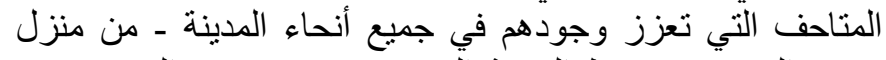

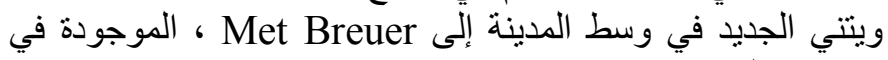
مساحتها السابقة.

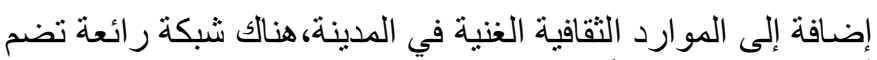

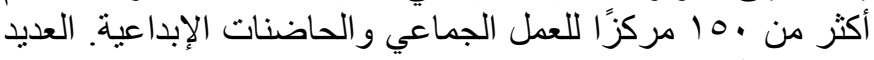

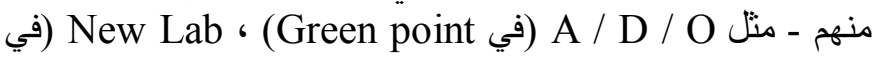
New Museum's NEW g (Brooklyn Navy Yard INC

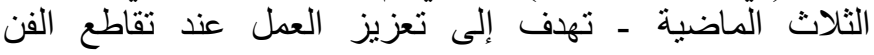

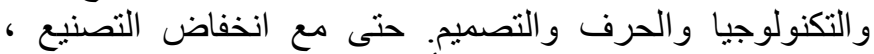

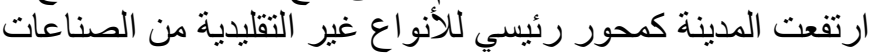

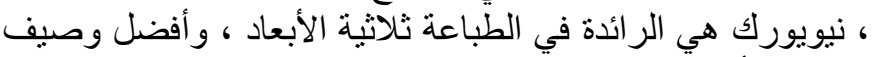

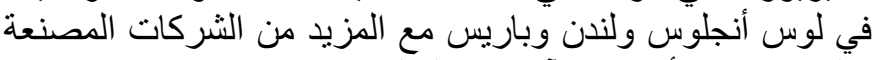

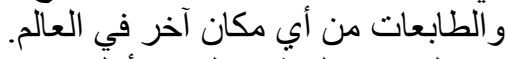

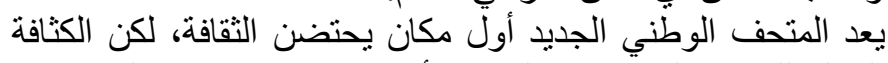

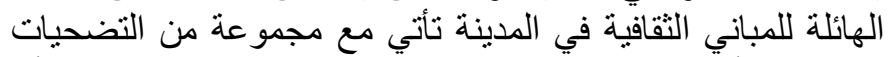

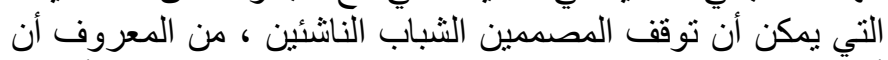

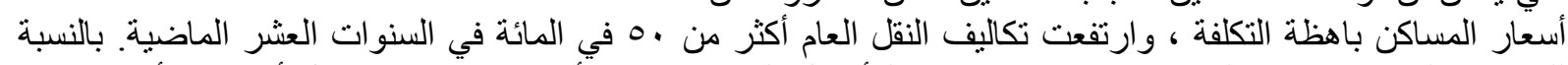

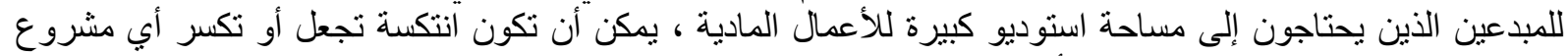

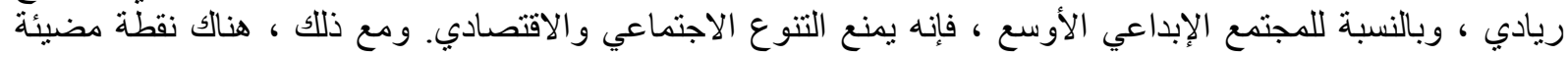


كبيرة لأولئك الذين يلتزمون بها: في شهر مايو ، أصدرت المدينة قانون Freelance ، وهو مجموعة من اللوائح لإنشاء

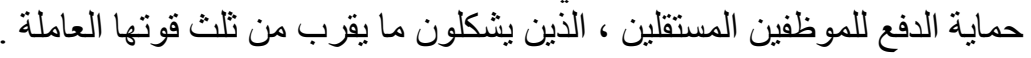

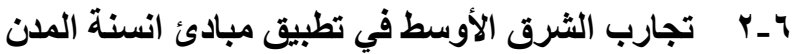

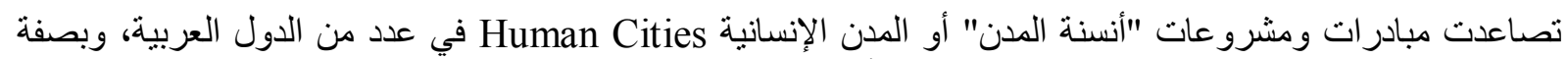

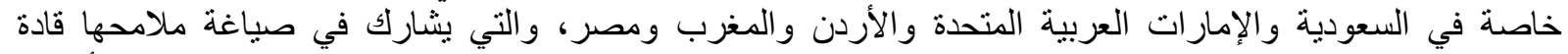

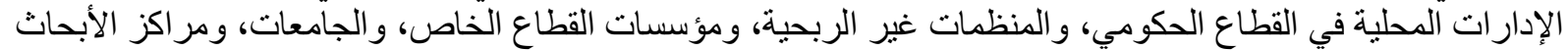

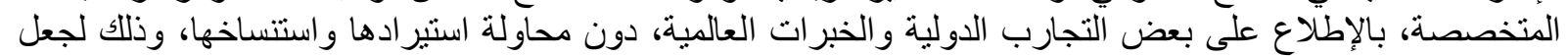

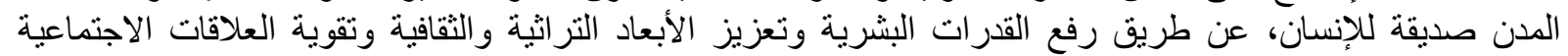

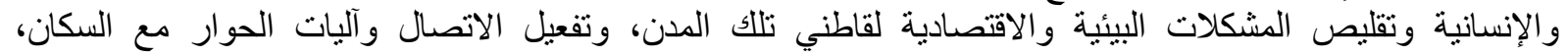

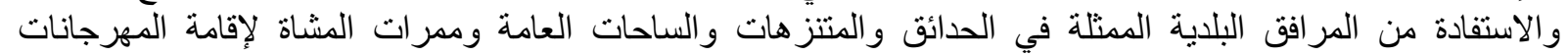

الترويجية.

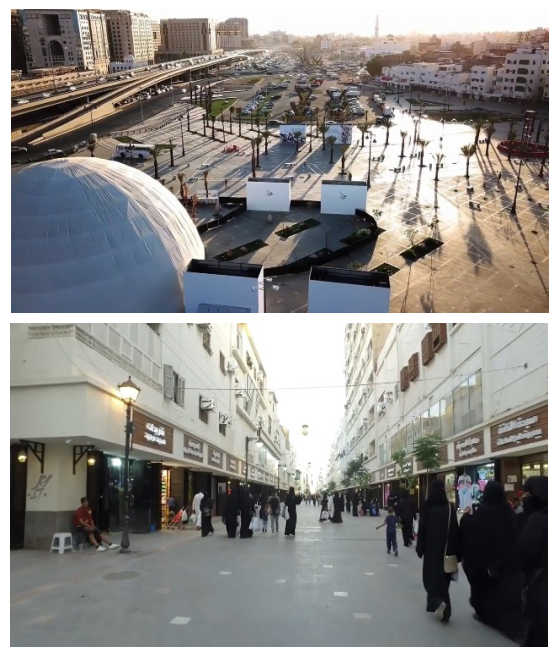

شكل رقم 19 ـ ـ تصميم الساحات العامة في المبات

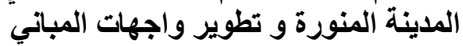

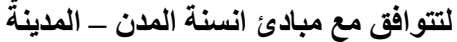
المنورة - المملكة العربية السعودية المبنة

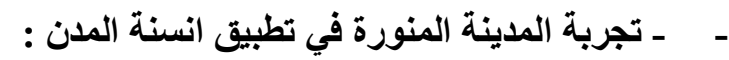

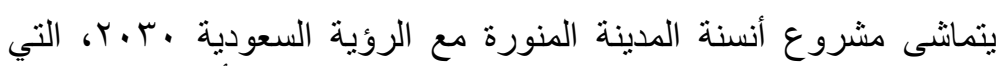

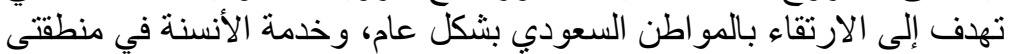

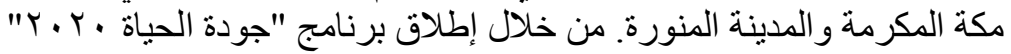

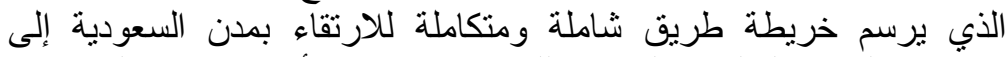

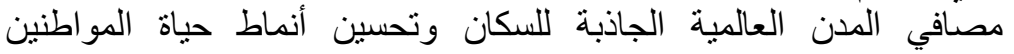

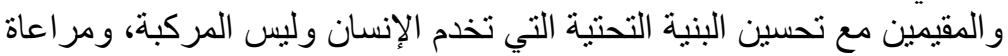
الاختلافات الاجتماعية.

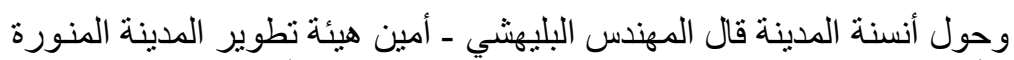

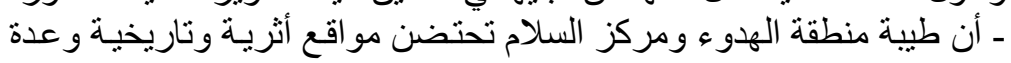

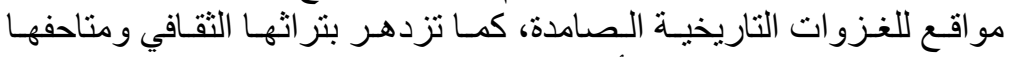

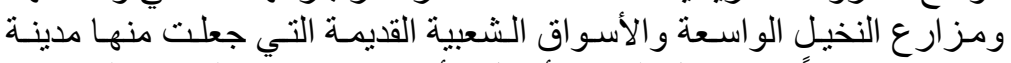

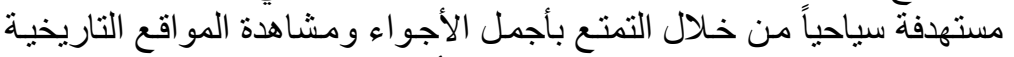

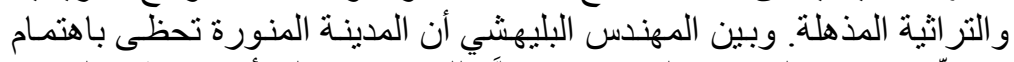

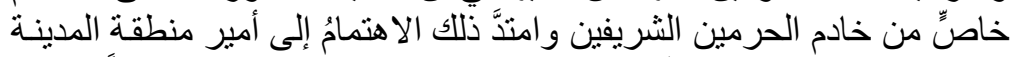

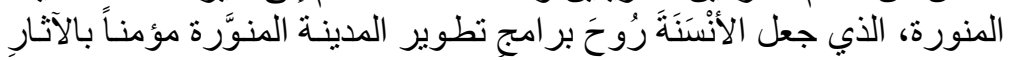

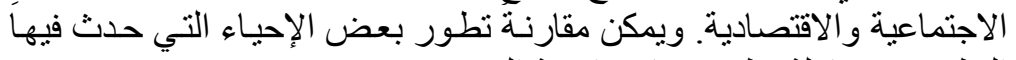
التطور و محاولة تطبيق مبادئ انسنة المدن.

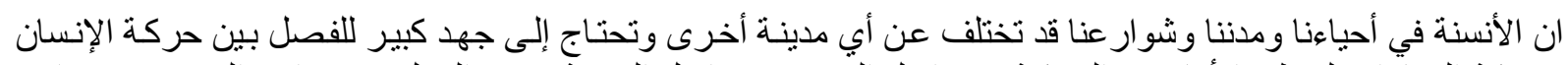

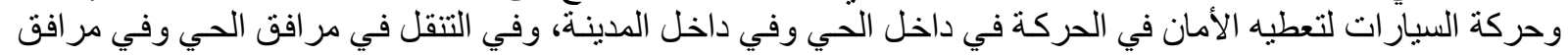

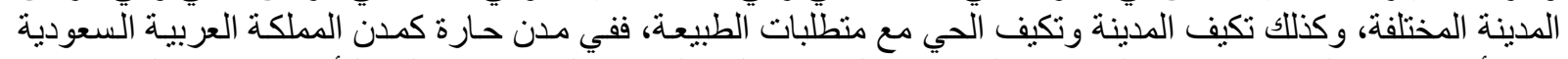

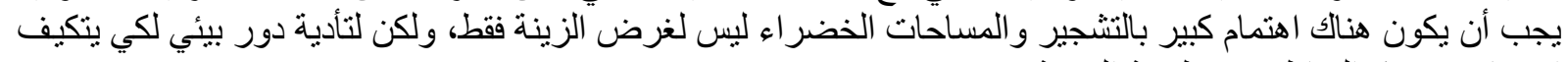
الإنسان في هذه المناطق مع طبيعة المدينة.

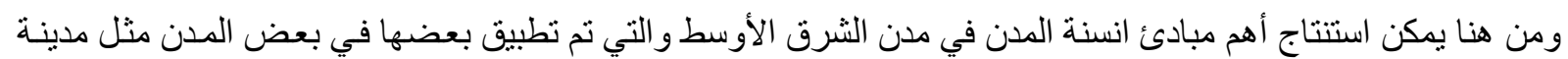

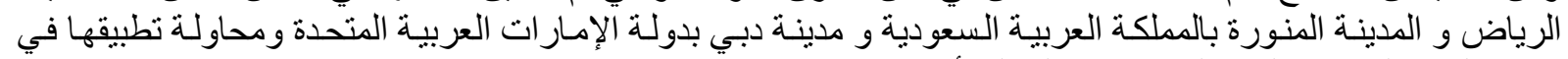

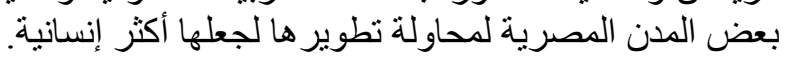

جدول ا مقارنة توضح كيفية التغيير الحادث في واجهات المباني السكنية لبعض أحياء المدنية المنورة بعد تطبيق بعض مبادئ النسئة النهائة المدن

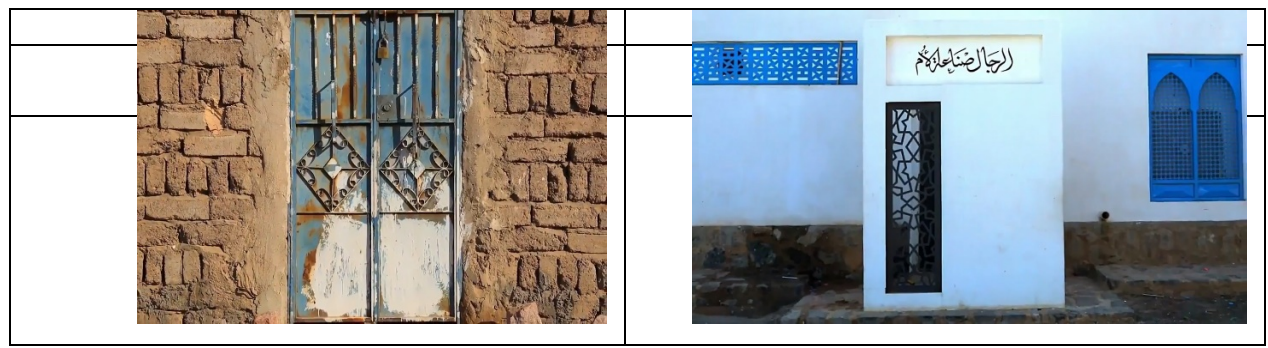




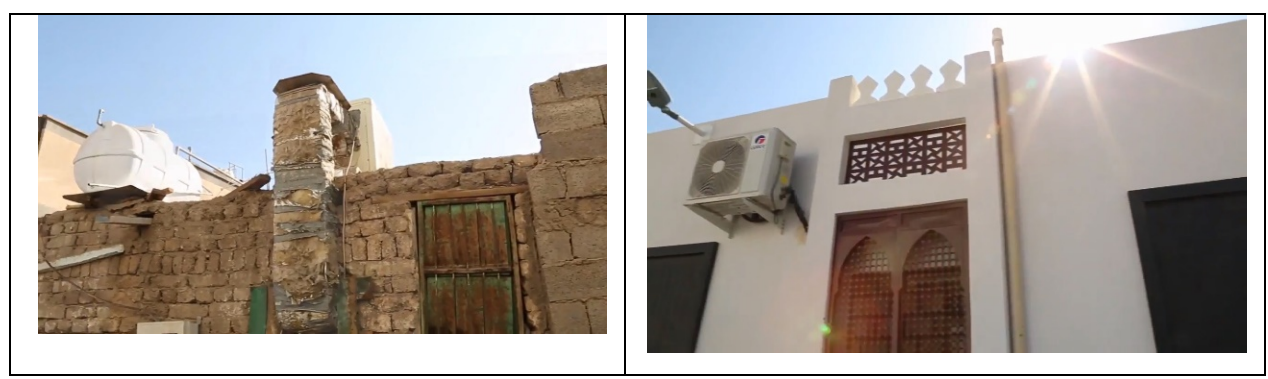

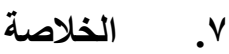 \\ 1-V}

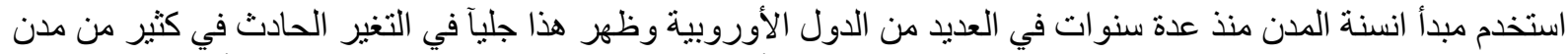

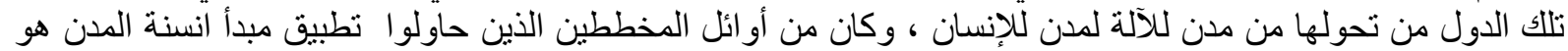

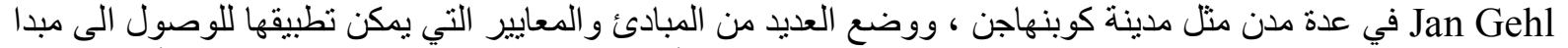

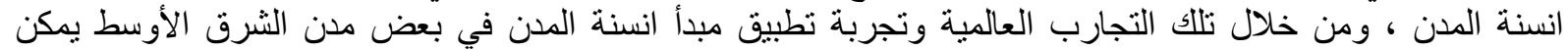
الوصول الى عدد من المبادئ التي يمكن استخدامها لتحقيق مبدأ الانسنة في المدن ومنئة التهاً:

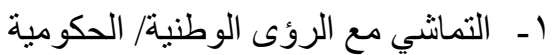

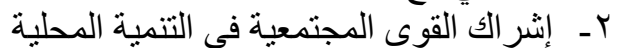

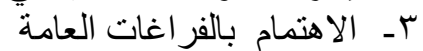
ـ ـ - التوازن بين الأصالة و المعاصرة المانة

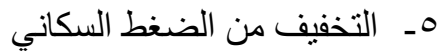

7- التو التب مع ملائمة الاعنبار آت البيائية

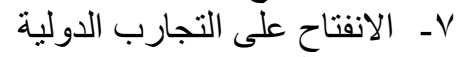

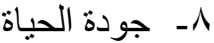

و هناك العديد من المفاهيم و القيم التي يبنى عليها مبدأ انسنة المدن لكي يمكن تحقيقه بالثكل المناسب في المدن و تطوير ها جدول ب بعض مبادئ انسنة المدن التي تم استتاجها من خلال البحث وجعلها أكثر انسانية

\begin{tabular}{|c|c|c|c|}
\hline صالحة للحياة & Green المناطق الخضراء & $\begin{array}{c}\text { تصميم مستدام } \\
\text { Sustainable Design }\end{array}$ & $\begin{array}{l}\text { الفن العام } \\
\text { Public Art }\end{array}$ \\
\hline التواصل الاجتماعي & Fountains ساحات عامة & $\begin{array}{c}\text { عamily } \\
\text { عائلية }\end{array}$ & $\begin{array}{c}\text { Habitat } \\
\text { Uلاماكن الحضرية Urban }\end{array}$ \\
\hline $\begin{array}{l}\text { صالحة للمشاة } \\
\text { Walkability }\end{array}$ & اجتماعية & $\begin{array}{c}\text { ذكية } \\
\text { Smart }\end{array}$ & \\
\hline Nature & $\begin{array}{c}\text { النمو الاقتصادي } \\
\text { Economic Growth }\end{array}$ & & \\
\hline
\end{tabular}

وبدأ هذا المبدأ في الظهور في الثرق الأوسط منذ عدة سنوات منمثلا في مدن المملكة العربية السعودية ودولة الإمارات

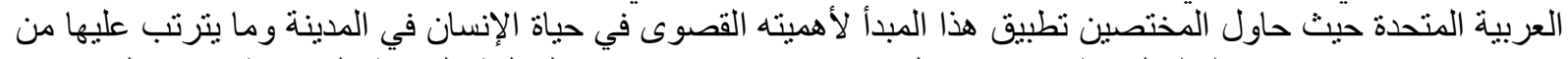

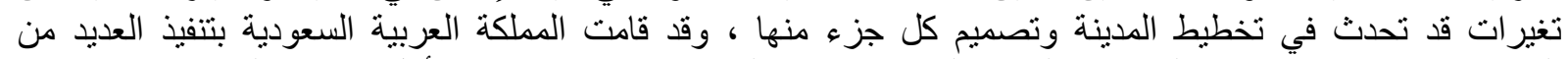

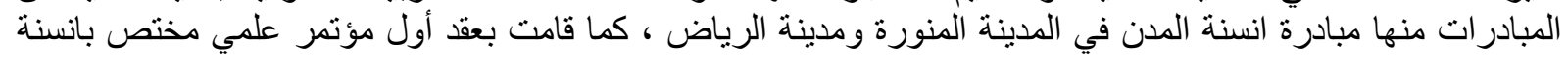
المدن.

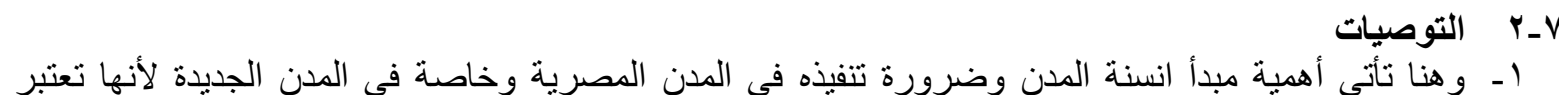

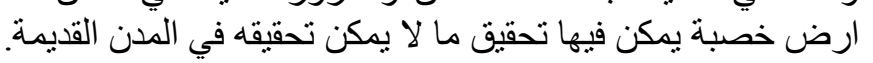

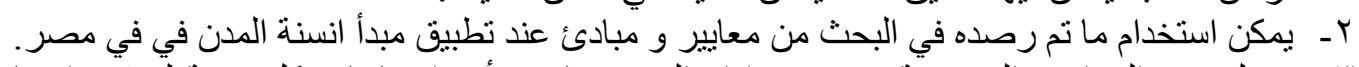

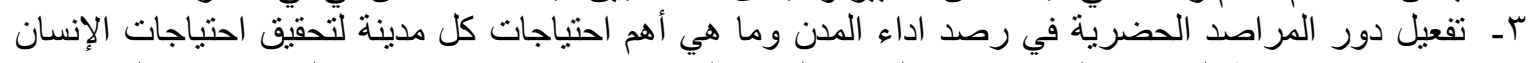

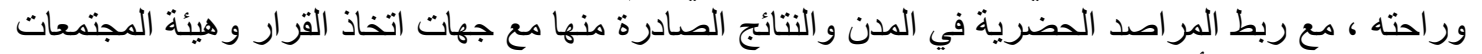

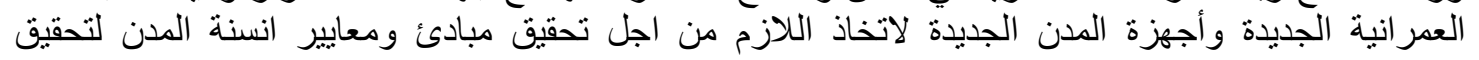

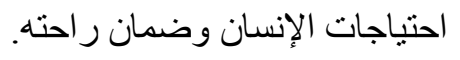




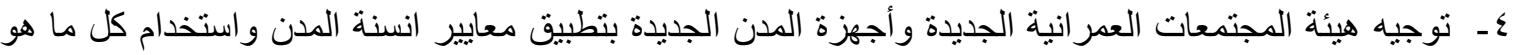

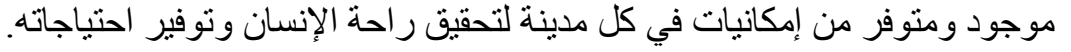

^. فرحات، باهر إسماعيل " العلاقة التبادلية بين السلوك الإنساني و البيئة المادية في الفر اغات العمر انية " ماجستير

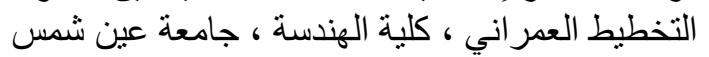

9. الدرديري، داليا حسين محمد " المعايير التخطيطية لتحقيق البعد الإنساني في المدينة العربية ( حالة دراسية مدينة

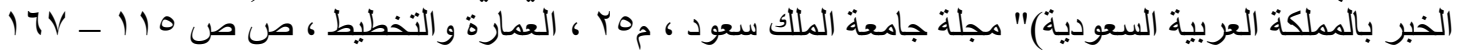

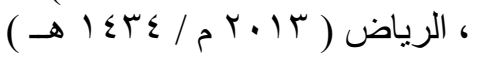

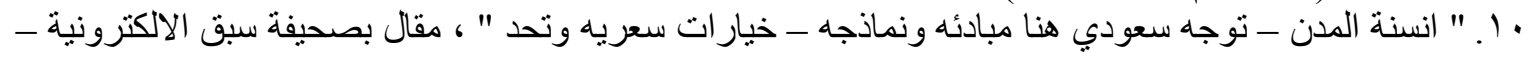

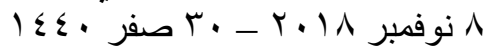

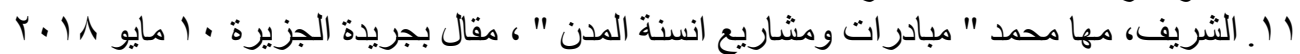

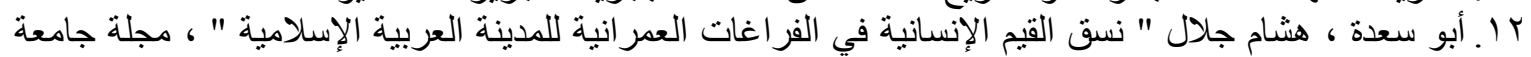

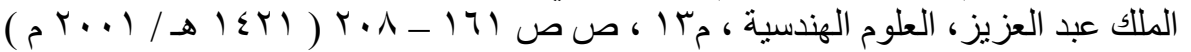
با "رفاهية البشر، لماذا تزايدت مبادرات انسنة المدن في الدول العربية " ، مركز المستقبل للأبحاث و الدراسات

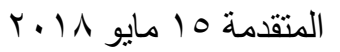

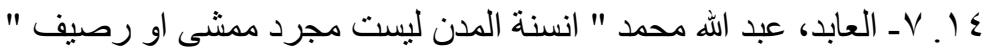

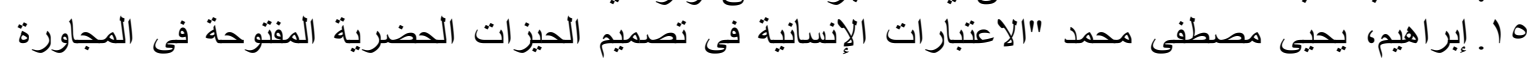

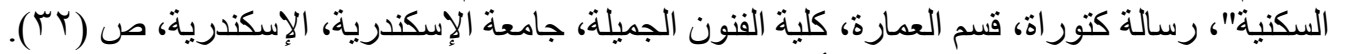

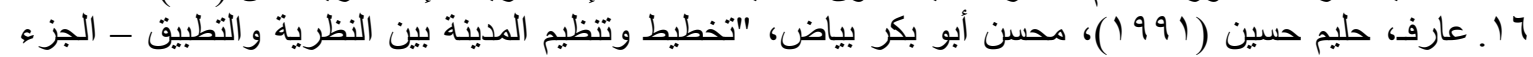

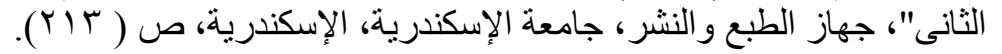

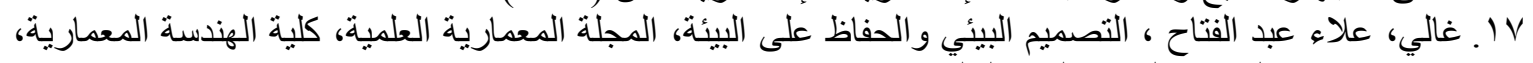

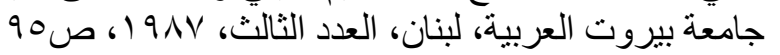

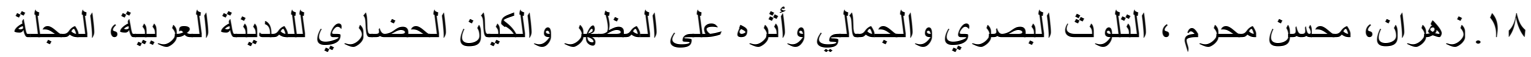

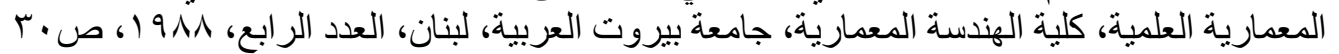

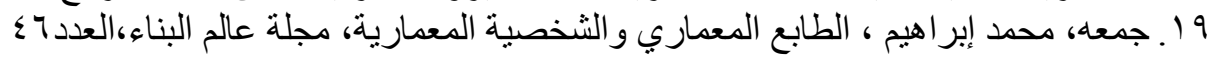

1. Grazia Concilio, Francesca Rizzo, " Human Smart City [Rethinking the interplay between design and planning] " Springer, link - http;//www.springer.om/series7906

2. Lori Jonses, " Public Spaces; How they Humanize Cities ", Health bridge - WBB trust Dhaka, October 2009.

3. Hans Kassenberg, Jeroen laven, Meredith Glaser\& Mattijs van't Hoff, " The City at Eye Level " , Eburon academic publishers, www.eburon.nl, 2016

4. Ola Gustafsson, Jan Gehl, "Walking and staying Cities - principles \& inspiration for moving and living sustainably in cities" 16 February 2017, moving sustainably conference, Turku, Finland.

5. Jan Gehl, Litt, " Cities for People ", Urban Quality Consultants, Copenhagen.

6. Mashary Al Naim," humanization of city Fabric - Riyadh city case study ", Riyadh newspaper 19 November 2016.

7. Mohamed AL Mahmood, Natalie Marie Gulsrud, Oliver Schulze, Trine Agervig Carstensen \& Gertrud Jorgensen, " Human-Centered public urban space ; exploring how the re-humanization of cities as on universal concept has been adopted and is experienced within the socio cultural context of Riyadh", link http;//doi.org/10.1080/17535069:2018.1539512, 28 October 2018

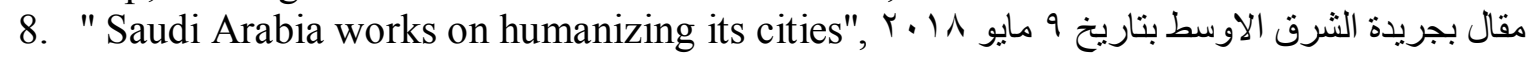

9. Brigitte cohin, " Unesco's vision for humanizing the city".

10. Sonia Alves " Cities for People", Lisboa, Universidad de Lisboa. 